\title{
Identifying, characterizing and predicting spatial patterns of lacustrine groundwater discharge
}

\author{
Christina Tecklenburg and Theresa Blume \\ Helmholtz Centre Potsdam, GFZ German Research Centre for Geosciences, Department of Hydrology, Potsdam, Germany \\ Correspondence to: Theresa Blume (blume@gfz-potsdam.de)
}

Received: 29 November 2016 - Discussion started: 13 December 2016

Revised: 28 July 2017 - Accepted: 31 July 2017 - Published: 6 October 2017

\begin{abstract}
Lacustrine groundwater discharge (LGD) can significantly affect lake water balances and lake water quality. However, quantifying LGD and its spatial patterns is challenging because of the large spatial extent of the aquiferlake interface and pronounced spatial variability. This is the first experimental study to specifically study these largerscale patterns with sufficient spatial resolution to systematically investigate how landscape and local characteristics affect the spatial variability in LGD. We measured vertical temperature profiles around a $0.49 \mathrm{~km}^{2}$ lake in northeastern Germany with a needle thermistor, which has the advantage of allowing for rapid (manual) measurements and thus, when used in a survey, high spatial coverage and resolution. Groundwater inflow rates were then estimated using the heat transport equation. These near-shore temperature profiles were complemented with sediment temperature measurements with a fibre-optic cable along six transects from shoreline to shoreline and radon measurements of lake water samples to qualitatively identify LGD patterns in the offshore part of the lake. As the hydrogeology of the catchment is sufficiently homogeneous (sandy sediments of a glacial outwash plain; no bedrock control) to avoid patterns being dominated by geological discontinuities, we were able to test the common assumptions that spatial patterns of LGD are mainly controlled by sediment characteristics and the groundwater flow field. We also tested the assumption that topographic gradients can be used as a proxy for gradients of the groundwater flow field. Thanks to the extensive data set, these tests could be carried out in a nested design, considering both small- and large-scale variability in LGD. We found that LGD was concentrated in the near-shore area, but alongshore variability was high, with specific regions of higher rates and higher spatial variability. Median inflow rates were
\end{abstract}

$44 \mathrm{~L} \mathrm{~m}^{-2} \mathrm{~d}^{-1}$ with maximum rates in certain locations going up to $169 \mathrm{Lm}^{-2} \mathrm{~d}^{-1}$. Offshore LGD was negligible except for two local hotspots on steep steps in the lake bed topography. Large-scale groundwater inflow patterns were correlated with topography and the groundwater flow field, whereas small-scale patterns correlated with grain size distributions of the lake sediment. These findings confirm results and assumptions of theoretical and modelling studies more systematically than was previously possible with coarser sampling designs. However, we also found that a significant fraction of the variance in LGD could not be explained by these controls alone and that additional processes need to be considered. While regression models using these controls as explanatory variables had limited power to predict LGD rates, the results nevertheless encourage the use of topographic indices and sediment heterogeneity as an aid for targeted campaigns in future studies of groundwater discharge to lakes.

\section{Introduction}

By linking groundwater with the surface water body, lacustrine groundwater discharge (LGD) can strongly control lake water quality and lake water budgets. Hence, all processes affecting quantity and quality of groundwater could also affect lake water quantity and quality (Winter et al., 1998; Rosenberry et al., 2015). To understand the vulnerability of groundwater-dominated lakes, it is not only important to know the total volume of groundwater lake exchange but also the spatial patterns of LGD (Meinikmann et al., 2013; Lewandowski et al., 2015). 


\subsection{Spatial patterns of lacustrine groundwater discharge and their potential controls}

In an isotropic homogenous aquifer, the exchange between groundwater and lake is expected to follow a distinct pattern along a 2-D transect: as sloping groundwater water tables meet the flat surface of the lake, groundwater inflow is strongest in close proximity to the shoreline and decreases exponentially with distance to the shore (McBride and Pfannkuch, 1975). However, isotropic and homogenous conditions rarely exist and spatial distribution of groundwater inflow differs strongly from lake to lake (Rosenberry et al., 2015). Experimental studies highlighted a large variety of observed exchange patterns including decreasing seepage with distance from the shoreline (McBride and Pfannkuch, 1975; Brock et al., 1982; Cherkauer and Nader, 1989; Kishel and Gerla, 2002), increasing seepage with distance from the shoreline (Cherkauer and Nader, 1989; Schneider et al., 2005; Vainu et al., 2015), local hotspots of offshore seepage (Fleckenstein et al., 2009; Ono et al., 2012) and a high smallscale variability in near-shore zones (Kishel and Gerla, 2002; Blume et al., 2013; Neumann et al., 2013; Sebok et al., 2013). Most often, complex hydrogeological settings are the reason for deviations from the theoretical pattern of LGD (Rosenberry et al., 2015). For example, it was found that offshore LGD was caused by local connections with a deeper aquifer (Fleckenstein et al., 2009; Ono et al., 2012) or resulted from local thinning of low permeable lake sediment (Cherkauer and Nader, 1989).

In general, the position of a lake in its regional groundwater flow system determines if a lake receives groundwater, loses water towards the groundwater or both (Born et al., 1979). As the groundwater flow field is often not well known, landscape topography can help to determine the groundwater flow field in humid regions and homogenous aquifers, where groundwater tables are assumed to follow the topography (Toth, 1963). However, Haitjema and Mitchell-Bruker (2005) found that the groundwater table is only topographically controlled if the ratio of groundwater recharge over hydraulic conductivity is sufficiently large and that often groundwater tables are indeed not topography, but recharge controlled (for a US-wide classification of these groundwater table controls, see also Gleeson et al., 2011).

Little is known about controls of small-scale variability of LGD. LGD is driven by the hydraulic gradients between lake and aquifer and controlled by the hydraulic conductivity. So far, there is no clear picture about the role of lake sediment characteristics in controlling LGD patterns and observations seem to be very site specific. For example, Kidmose et al. (2013) found that low permeable lacustrine sediments can completely prevent groundwater upwelling, whereas Vainu et al. (2015) observed LGD through low permeable lacustrine sediments. Kishel and Gerla (2002) associated small-scale variabilities in LGD with small-scale heterogeneities in hydraulic conductivities (Kishel and Gerla,
2002); Schneider et al. (2005) found no correlation between seepage rates and sediment characteristics.

Methods used in these studies include seepage meters (e.g. Kidmose et al., 2013; Kishel and Gerla, 2002; Schneider et al., 2005; Vainu et al., 2015) and piezometers (Kishel and Gerla, 2002). Two other methods have also been used successfully to investigate exchange patterns between lakes and groundwater: fibre-optic distributed temperature sensing (FO-DTS) (Blume et al., 2013; Sebok et al., 2013) and vertical temperature profiles (VTPs) (Blume et al., 2013; Meinikmann et al., 2013; Neumann et al., 2013; Sebok et al., 2013). Both methods use heat as a tracer. The measurement of radon activities can also help to identify groundwater inflows (Kluge et al., 2012; Ono et al., 2012; Shaw et al., 2013). Existing lake studies have investigated LGD patterns with either a high spatial resolution $\left(1-2 \mathrm{~m}^{2}\right)$ but a local focus $(10 \mathrm{~m} \times 17 \mathrm{~m}-25 \mathrm{~m} \times 6 \mathrm{~m})$ (Kishel and Gerla, 2002; Blume et al.; 2013; Sebok et al., 2013) or focused on the entire lake but used a relatively low spatial resolution (measurements along the shoreline every 200-3000 m) (Schneider et al., 2005; Meinikmann et al., 2013; Shaw et al., 2013). However, the experimental effort required rarely allows their extension to cover the lateral, alongshore dimension in sufficient extent and detail to identify the spatial variability and patterns of LGD along the shoreline.

\subsection{Objectives}

Identifying the processes and structures controlling LGD patterns is the key to predicting them reliably (Grimm, 2005). The aim of this study is the characterization of inflow patterns as well as the identification of their controls. The ability to identify patterns and their controls strongly depends on the spatial resolution and the extent of the applied experimental methods. By taking measurements with a high spatial resolution over large parts of the lake, we are closing the observational gap between high-resolution "plot"-scale studies (focusing on a small shoreline segment) and low-resolution larger-scale studies (see Sect. 1.2) and opening the possibility to truly investigate not only shore-lake transects or plots but alongshore spatial variability and patterns of LGD.

The study design aimed at answering the following research questions:

- How does LGD vary in space and time?

- What are the relative roles of sediment permeability, local topography and regional groundwater discharge for spatial patterns of LGD?

- Can we use LGD patterns to test if groundwater tables are topography controlled?

We investigated these research questions at Lake Hinnensee, a typical post-glacial lake located in the intensively monitored TERENO observatory in the lowland landscape of northeast Germany. Strong water level declines observed 
in the last decades at this lake as well as at others in the region are currently under investigation. This lake system has the additional advantage that the upper unconfined aquifer in which the lake rests can be considered largely homogeneous and isotropic (sandy sediments of a glacial outwash plain; no bedrock control). Therefore, LGD patterns are unlikely to be dominated by geological discontinuities, and we were able to test the common assumptions that spatial patterns of LGD are controlled by sediment characteristics and topography as a proxy for gradients of the groundwater flow field.

To identify LGD patterns, we measured VTPs in the nearshore area and used FO-DTS measurements and radon sampling in the offshore area. VTPs were used to quantify LGD rates, whereas FO-DTS measurements and radon sampling were used as qualitative tracers to detect the presence or absence of offshore LGD.

\section{Methods}

\subsection{Study site}

Lake Hinnensee is located in northeast Germany in the Müritz National Park $\left(53^{\circ} 19^{\prime} 30.6^{\prime \prime} \mathrm{N}, 13^{\circ} 11^{\prime} 16.2^{\prime \prime} \mathrm{E}\right)$ and is one of the focus areas of the TERENO observatory northeast Germany. The landscape of the Müritz National Park was shaped by the last glaciation and is dominated by lakes. Lake Hinnensee was formed as a glacio-fluvial tunnel valley and is located within the outwash plain. Bore logs of the 16 observation wells installed around the lake show largely homogeneous sandy sediments. The terminal moraine is situated north of the lake (Fig. 1). Lake Hinnensee has a mean depth of $7 \mathrm{~m}$ with a maximum depth of $14 \mathrm{~m}$ and is connected to a lake called Großer Fürstenseer See in the south. The two lakes together cover an area of $2.68 \mathrm{~km}^{2}$; the size of Lake Hinnensee is $0.49 \mathrm{~km}^{2}$. The lake system has no surface water inflow or outflow, apart from a two minor ditches connected with the Großer Fürstenseer See that only become active at very high lake level. Since 2011, when the first LGD measurements were conducted at Lake Hinnensee, the ditches were only active for a period of 4 months (maximum observed inflow: $0.0083 \mathrm{~m}^{3} \mathrm{~s}^{-1}, 22$ February 2012; maximum observed outflow: $0.0030 \mathrm{~m}^{3} \mathrm{~s}^{-1}, 11$ May 2012). The connection to Großer Fürstenseer See is not assumed to influence LGD patterns of Lake Hinnensee, as the general flow direction of the groundwater flow field runs from north to south, with water leaving the lake system at the southern end of Großer Fürstenseer See. The relief of the lake catchment is hilly in the north, with steep slopes down to the lake and more gentle slopes and lower elevations towards the south (Fig. 1). Elevations range between 63 and $115 \mathrm{ma.s.l}$. The lake is surrounded by forest. The mean annual precipitation is $610 \mathrm{~mm}$ and the mean annual temperature is $8.1^{\circ} \mathrm{C}(1901-$ 2005 Neustrelitz, DWD - German Weather Service).

\subsection{Estimating lacustrine groundwater discharge}

We applied three different methods to determine LGD patterns: VTPs in the near-shore region, and FO-DTS and radon in the offshore area. The VTPs allowed us to determine LGD rates by using the analytical solution of the heat transport equation, while the other methods were only used as indicators for the presence and absence of LGD. As the main body of the study focuses on the temperature-based methods, the radon methodology and results are described in Appendix A.

\subsubsection{Near-shore LGD derived from vertical temperature profiles (VTPs)}

VTPs were used to estimate the spatial variability of LGD rates along the shoreline. Profiles were measured $50 \mathrm{~cm}$ away from the shoreline every $10 \mathrm{~m}$ along $2.39 \mathrm{~km}$ of the shoreline. The data set covers $62 \%$ of the total shoreline (Fig. 1). The VTPs were measured during five field campaigns in $\mathrm{Au}-$ gust 2011, June and July 2012, and January and July 2013 (Table 1, Fig. 1). In July 2013, sediment temperatures were additionally measured in $150 \mathrm{~cm}$ distance from the shoreline in order to analyse the trend of LGD with increasing distance to the shore. Measurements in August 2011 and January 2013 were conducted only on a $350 \mathrm{~m}$ long subsection of the shoreline in the northeast of the lake in order to analyse the temporal stability of the observed patterns (Fig. 1).

One VTP consisted of six temperature measurements: one at the sediment-water interface and five in the saturated sediment at 5, 10, 20,30, and $40 \mathrm{~cm}$ depths. Temperatures were measured with a high-precision digital thermometer (Greisinger GMH 3750) and a corresponding Pt100 thermistor with an accuracy of $\pm 0.03^{\circ} \mathrm{C}$. The needle had a length of $45 \mathrm{~cm}$ and a diameter of $3 \mathrm{~mm}$.

LGD was calculated from the measured VTP using the analytical solution of the 1-D heat flow equation from Bredehoeft and Papaopulos (1965). Assuming a vertical water flux along the temperature profile and steady-state temperatures at the sediment-water interface, sediment temperature at a specific depth is calculated as follows:

$T_{\bmod (z)}=\frac{\exp ^{\frac{q_{z} \cdot p_{\mathrm{f}} c_{\mathrm{f}} \cdot z}{k_{\mathrm{fs}}}}-1}{\exp ^{\frac{q_{z} \cdot p_{\mathrm{f}} c_{\mathrm{f}} \cdot L}{k_{\mathrm{fs}}}}-1} \cdot\left(T_{\mathrm{L}}-T_{0}\right)+T_{0}$,

where $q_{z}$ is the vertical water flux $\left(\mathrm{m} \mathrm{s}^{-1}\right)$ (positive for groundwater gaining), $p_{\mathrm{f}} c_{\mathrm{f}}$ is the volumetric heat capacity of the fluid $\left(\mathrm{J} \mathrm{m}^{-3} \mathrm{~K}^{-1}\right), z$ is the depth below the upper boundary $(\mathrm{m}), k_{\mathrm{fs}}$ is the thermal conductivity of the sediment $\left(\mathrm{J} \mathrm{s}^{-1} \mathrm{~m}^{-1} \mathrm{~K}^{-1}\right), L$ is the extent of the exchange zone and the depth of the lower boundary $(\mathrm{m})$, and $T_{\mathrm{L}}$ is the temperature of the lower and $T_{0}$ of the upper boundary $\left({ }^{\circ} \mathrm{C}\right)$. The values of $p_{\mathrm{f}} c_{\mathrm{f}}$ of water and $k_{\mathrm{fs}}$ of lake sediment were taken from Stonestrom and Constantz (2003). $p_{\mathrm{f}} c_{\mathrm{f}}$ of water was set to $4.19 \times 10^{6} \mathrm{~J} \mathrm{~m}^{-3} \mathrm{~K}^{-1}$ and $k_{\mathrm{fs}}$ to $2 \mathrm{~J} \mathrm{~s}^{-1} \mathrm{~m}^{-1} \mathrm{~K}^{-1}$, a typical 


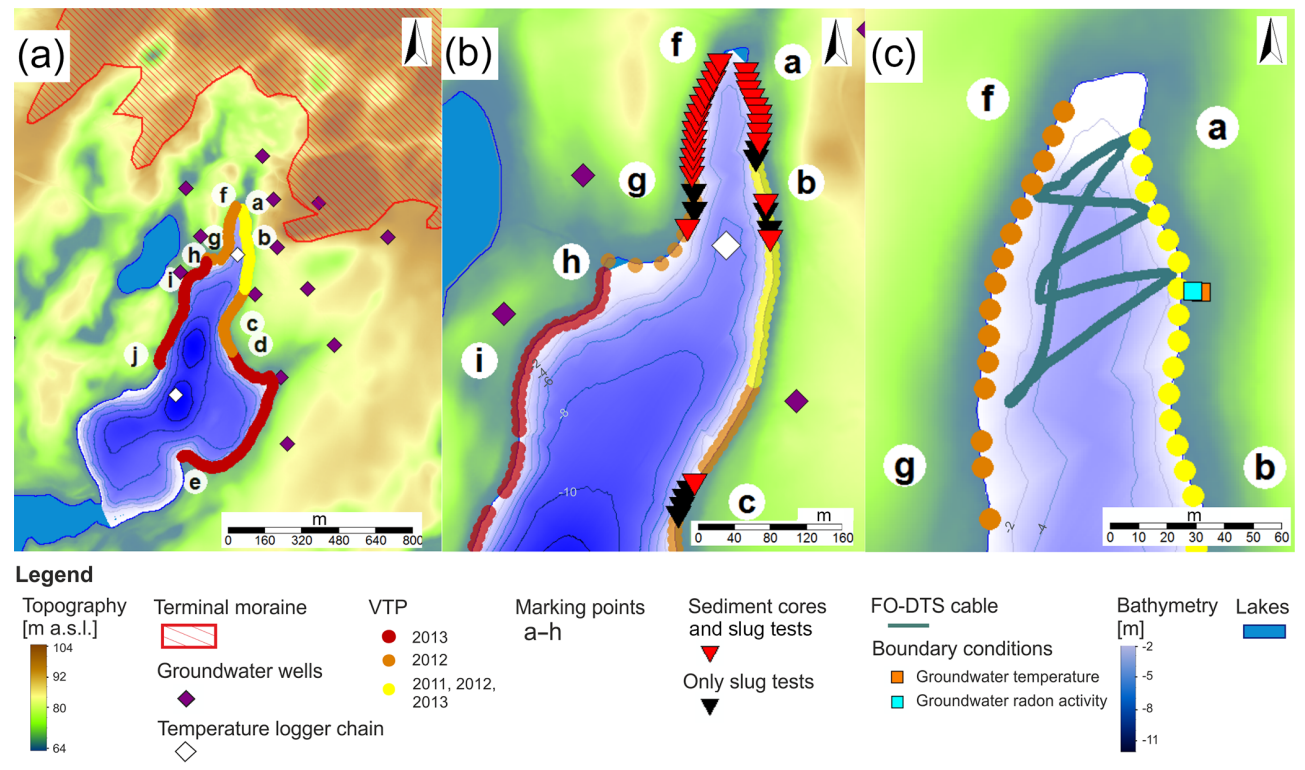

Figure 1. Study site and experimental infrastructure. (a) Overview of the study site with VTP measurement and locations of groundwater wells and temperature logger chains, (b) slug test and sediment core sampling locations and (c) FO-DTS cable installation in the northern part of the lake.

Table 1. Dates, boundary conditions and use of vertical temperature profile surveys.

\begin{tabular}{lrrl}
\hline Date & $\begin{array}{r}\text { Groundwater } \\
\text { temperature }\left({ }^{\circ} \mathrm{C}\right)\end{array}$ & $\begin{array}{r}\text { Lake water } \\
\text { temperature }\left({ }^{\circ} \mathrm{C}\right)\end{array}$ & Data analysis \\
\hline 24-25 Aug 2011 & 10.7 & 22.7 & Temporal stability of LGD patterns \\
12-14 Jun 2012 & 8.9 & 18.2 & Spatial patterns of LGD along the shoreline \\
16-17 Jul 2012 & 10.1 & 20.1 & Spatial patterns of LGD along the shoreline \\
21-23 Jan 2013 & 7.0 & 0.0 & Spatial patterns of LGD along the shoreline \\
17-25 Jul 2013 & $10.1-10.3$ & 23.2 & Spatial patterns of LGD along the shoreline and LGD \\
& & patterns with increasing distance from the shore \\
\hline
\end{tabular}

value for sandy sediment, which was the dominant grain size in the upper metre of lake sediment.

Usually, the upper boundary is the sediment-water interface (Schmidt et al., 2006; Blume et al., 2013; Meinikmann et al., 2013). However, at locations with shallow water depths in lakes, temperatures in the near-surface sediments can be strongly affected by daily temperature variations and thus violate the upper boundary condition of the steady-state model. To avoid unreliable LGD calculations due to biased temperatures at the upper boundary, we instead used the temperatures measured at $10 \mathrm{~cm}$ sediment depth. A shift of the upper boundary from the sediment-water interface to a depth of $10 \mathrm{~cm}$ had a negligible effect on the estimation of the LGD rate assuming steady-state conditions. This was validated with theoretical temperature profiles. A shift of the boundary condition to a depth of $10 \mathrm{~cm}$ caused a maximal deviation in the estimation of exchange rates of $1 \mathrm{~L} \mathrm{~m}^{-2} \mathrm{~d}^{-1}$ and the error decreased with increasing flow rates.
For the lower boundary, we used the shallow groundwater temperature measured in close proximity to the lake (Fig. 1c). For the length of the exchange zone, we tested different values. The quality of LGD estimation increased with increasing $L$ but was insensitive for values larger than $3 \mathrm{~m}$. Thus, $L$ was set to $3 \mathrm{~m}$.

The exchange rate was optimized by minimizing the root mean square error (RMSE) between measured and calculated sediment temperatures, as described in Schmidt et al. (2006):

$\mathrm{RMSE}=\sqrt{\frac{1}{n} \sum\left(T_{\text {meas }(z)}-T_{\bmod (z)}\right)^{2}}$.

The quality of the fit between measured and modelled sediment temperature was also visually checked using plots of the measured and modelled VTPs. Fits with RMSE greater than or equal to $0.4{ }^{\circ} \mathrm{C}$ were not used for further analyses as differences between modelled and measured data were considered too large. 
Estimated LGD values were analysed for their lateral spatial variability using VTPs measured at a distance of $50 \mathrm{~cm}$ from the shoreline, for their trend with increasing distance from the shore using VTPs measured at 50 and $150 \mathrm{~cm}$ distances from the shore and for their temporal stability using VTPs measured in the different years (Table 1).

Spatial variability and correlation of LGD along different distances along the shoreline were analysed using autocorrelation plots and autocorrelation values $(|\rho|)$ as described in Caruso et al. (2016). High autocorrelation indicates that LGDs along a given stretch of the shoreline are correlated (i.e. if LGD is high in a certain location, it is also likely to be high at $10 \mathrm{~m}$ distance), whereas $|\rho|<0.2$ indicates that LGDs are uncorrelated and strong spatial variability exists.

In order to analyse the temporal stability of spatial patterns, we used the differences between the LGD rates measured at different points in time and calculated the correlation between the VTP surveys using Spearman's rank correlation coefficient $(\rho)$. Correlations were regarded as significant for $p$ values smaller than 0.05 .

To test if single sediment temperature measurements instead of profiles could be used as a quickly measurable qualitative indication for LGD spatial patterns, we determined the correlations between sediment temperatures at all individual depths with LGD rates determined from the full profiles.

\subsubsection{Lake sediment temperature anomalies as indicators for offshore LGD based on fibre-optic distributed temperature sensing (FO-DTS)}

To identify offshore groundwater inflow patterns, we measured sediment surface temperatures with a $500 \mathrm{~m}$ long FODTS cable installed permanently along six transects through the northern part of the lake (Fig. 1c). Two divers ensured good contact of the cable to the lake sediment and also tracked the location of the cable with a differential GPS system (Topcon GR-3) installed on a buoy.

The technology of the FO-DTS is based on the detection of the Raman scattering of a laser pulse through the optical fibre (Ukil et al., 2012). For our measurements, we used a Sensornet Halo device with a sampling resolution of $2 \mathrm{~m}$ and a measurement precision of $0.05^{\circ} \mathrm{C}$.

We carried out two measurement campaigns: in February and in August 2014 (Table 2). In February, the DTS measurements were taken between 18:49 and 19:17 CEST with a temporal resolution of $2 \mathrm{~min}$. We used a single-ended setup with a double-ended mode (four channels, two in each direction) and two calibration baths: a warm bath $\left(25.5^{\circ} \mathrm{C}\right)$ at one end and a cold bath $\left(0^{\circ} \mathrm{C}\right)$ at the other end.

In the second campaign, from 27 to 28 August 2014, measurements extended over $24 \mathrm{~h}$, from $18: 43$ on the 27 th until 18:45 CEST the next day with a temporal resolution of 2 min. The setup was the same as in February, but additionally both cable ends were run through the cold bath (warm bath: $20.9{ }^{\circ} \mathrm{C}$; cold bath: $0.1^{\circ} \mathrm{C}$ ).
The trend and offset in the DTS temperature data were corrected using external temperature loggers in the calibration baths (February: Greisinger GMH 3750, accuracy: $\pm 0.03{ }^{\circ} \mathrm{C}$; August: HOBO TidbiT v2 water temperature data logger, accuracy: $\pm 0.21^{\circ} \mathrm{C}$ ).

All four channels showed the same pattern with only small differences in absolute temperature values, and further analyses were based on one of the four traces. Sediment temperatures in August were strongly affected by solar radiation. Analysis of $24 \mathrm{~h}$ amplitude or daily minimum temperature did not provide useful information of groundwater inflow patterns as the impact of solar radiation was too strong and spatially variable. Sebok et al. (2013) recommended using nighttime data to avoid the uncertainties caused by solar radiation. However, at night, shallow near-shore water cooled down and it was not easy to distinguish if temperature shifts resulted from groundwater inflow or from a decrease of water temperature due to decreasing air temperature. We thus chose a time window in which the temperatures at the near-shore shallow region and in the deeper region of the lake were very similar and groundwater inflow induced temperature shifts were easy to identify. This time window was from 18:43 to 19:11 CEST on 27 August.

Temperature depth profiles of the lake were available with $1 \mathrm{~m}$ spatial resolution (HOBO Water Temperature Pro v2 data logger, accuracy: $\left.\pm 0.21^{\circ} \mathrm{C}\right)$. In winter, we had only one profile in the central part of the lake, but in August a second profile further north was available (Fig. 1a and b). The groundwater temperature was measured in a piezometer (OTT Orpheus Mini, accuracy: $\pm 0.5^{\circ} \mathrm{C}$ ) close to the lake (Fig. 1c) and air temperature data were available from a weather station $1.5 \mathrm{~km}$ away, and in August an additional air temperature data logger (of the same type as used for the water profiles) was installed directly at the lake.

\subsection{Identifying controls of LGD patterns}

In order to identify the controls of the observed LGD patterns, we characterized both the near- and far-field conditions and correlated these characteristics with LGD rates using Spearman's rank correlation coefficient. At the local scale (near-field conditions) this includes sediment characteristics, while at the larger scale (far-field conditions) we considered topographic indices and the groundwater flow field as the most likely controls.

\subsubsection{Sediment heterogeneity as a small-scale control on LGD patterns}

\section{Hydraulic conductivity from slug tests}

At 37 VTP positions (Fig. 1b), slug tests were performed to estimate hydraulic conductivity $\left(k_{\text {sat }}\right)$ of the near-surface sediment. Slug tests were carried out in piezometers with an inner diameter of $36.4 \mathrm{~mm}$. The screen placed on the lower 
Table 2. Groundwater temperatures and lake water temperature depth profiles measured during FO-DTS campaigns.

\begin{tabular}{lrrr}
\hline Date & $\begin{array}{r}\text { Air temperature } \\
\left({ }^{\circ} \mathrm{C}\right)\end{array}$ & $\begin{array}{r}\text { Groundwater temperature } \\
\left({ }^{\circ} \mathrm{C}\right)\end{array}$ & $\begin{array}{r}\text { Temperature depth profile } \\
\left({ }^{\circ} \mathrm{C}\right)\end{array}$ \\
\hline 20 Feb 2014 & $6.8^{1}$ & 6.3 & $0 \mathrm{~m}: 1.8$ \\
& & & $-1 \mathrm{~m}: 3.4$ \\
& & & $-2 \mathrm{~m}: 3.4$ \\
& & & $-4 \mathrm{~m}: 3.4$ \\
& $19.4^{1}$ & 11.6 & $-5 \mathrm{~m}: 3.4$ \\
\hline 27 Aug 2014 & $16.1^{2}$ & & $0 \mathrm{~m}: 18.9$ \\
& & & $-1 \mathrm{~m}: 18.7$ \\
& & & $-2 \mathrm{~m}: 18.7$ \\
& & $-4 \mathrm{~m}: 18.5$ \\
& & $-5 \mathrm{~m}: 18.4$ \\
\hline
\end{tabular}

${ }^{1}$ Measured at the nearby weather station. ${ }^{2}$ Measured close to the lake.

end of the piezometer had a length of $10 \mathrm{~cm}$ and consisted of $4 \mathrm{~mm}$ diameter perforations in the PVC tube wrapped with fine mesh. The midpoint of the screen was $50 \mathrm{~cm}$ below the sediment surface. To minimize interference with the temperature profile measurements, the piezometers were installed at $50 \mathrm{~cm}$ distance. For the rising-head tests, water was quickly removed out of the piezometer using a peristaltic pump. Recovery of the water table was measured with automatic pressure logger (HOBO $13 \mathrm{ft}$ freshwater level data logger, accuracy: $\pm 0.3 \mathrm{~cm}$ ) with a temporal resolution of $1 \mathrm{~s}$. Recovery data were then analysed using the approach of Hvorslev (1951):

$k_{\mathrm{sat}}=\frac{\pi r^{2}}{T_{0} c}$,

where $r$ is the radius of the piezometer, $T_{0}$ the time needed to recover $37 \%$ of initial water level and $c$ a shape factor. The shape factor depends on the ratio of screen length and radius. The piezometer had a screen length radius ratio of 5.5, and thus we used a shape factor introduced by Chapuis (1989), valid for wells with ratio smaller than 8 :

$c=4 \pi r \sqrt{\frac{L}{2 r}+\frac{1}{4}}$,

where $L$ is the length of the screen.

\section{Grain size distributions from sediment cores}

Sediment cores were taken from 30 selected slug test positions (Fig. 1b). Sediment cores were taken with a transparent tube with an inner diameter of $32 \mathrm{~mm}$. The length of cores varied between 42 and $145 \mathrm{~cm}$, with the majority of core lengths between 80 and $128 \mathrm{~cm}$. Each core was split into samples according to the visible sediment layers. The samples were oven-dried at a temperature of $105^{\circ} \mathrm{C}$ and sieved with a vibratory sieve shaker (Retsch AS 200). The sieving setup included the following mesh sizes: 0.063 , $0.125,0.2,0.3,0.5,0.63,2,5$ and $10 \mathrm{~mm}$. Grain sizes smaller than $0.063 \mathrm{~mm}$ were classified as silt, grain sizes larger than $0.063 \mathrm{~mm}$ but smaller than $0.2 \mathrm{~mm}$ as fine sand, larger than $0.2 \mathrm{~mm}$ but smaller than $0.63 \mathrm{~mm}$ as medium sand, larger than $0.63 \mathrm{~mm}$ but smaller than $2 \mathrm{~mm}$ as coarse sand and larger than $2 \mathrm{~mm}$ as gravel.

For the correlation analyses between sediment characteristics and LGD, we used only samples taken from the upper $100 \mathrm{~cm}$ of the lake sediment. The mean of each grain size fraction was calculated for each sampling location from all single samples of the upper $100 \mathrm{~cm}$ in which the core was split. In addition to the correlation analyses, simple and multiple linear regression models were calculated between LGD and each grain size fraction. For the calculation of the multiple linear regression models, correlations between explanatory variables were checked before and variables were regarded to be independent from each other if $\rho$ was below 0.7 . Models were regarded as significant if $p$ values were below 0.05 . The goodness of fit of the models was estimated with the coefficient of determination $\left(R^{2}\right)$.

\subsubsection{Topographic indices as controls on large-scale LGD patterns}

In order to analyse the effect of far-field conditions on LGD patterns, the following topographic indices were calculated using SAGA GIS: average elevation, average slope and the percentage of area with low topographic gradient in direct proximity to the lake shore. To determine the topographic indices, we used a digital elevation model (DEM) of the area with a resolution of $1 \mathrm{~m}$. The topographic indices were estimated for representative areas, i.e. upslope areas for shoreline sections of $100 \mathrm{~m}$ length. Therefore, the shoreline was 
split into 46 subsections of $100 \mathrm{~m}$ length with an overlap of $50 \mathrm{~m}$. As upslope areas can only be determined for points, not for lines, we calculated upslope areas every metre along the shoreline and aggregated them to one upslope area for each subsection. The upslope areas were determined using the multiple flow direction approach. To investigate the topographical zone of influence (zi), four different extents of the upslope areas were considered at 25, 50, 100 and $200 \mathrm{~m}$ distances from the shoreline. These zones of influence will be called $\mathrm{zi}_{25 \mathrm{~m}}, \mathrm{zi}_{50 \mathrm{~m}}, \mathrm{zi}_{100 \mathrm{~m}}$ and $\mathrm{zi}_{200 \mathrm{~m}}$ in the following. The indices' slope and elevation were averaged over each upslope area (arithmetic mean). The percentage of area with low topographic gradient was here defined as the percentage of the upslope area not to be higher than $50 \mathrm{~cm}$ above lake level in direct vicinity of the lake shore. This threshold was chosen as this was the area flooded at maximum lake levels known within the last 25 years. Indices were correlated with median LGD rates for the $100 \mathrm{~m}$ long subsections derived from VTPs using Spearman's rank correlation coefficient. Each subsection included 10 VTP measurement locations. Furthermore, simple and multiple linear regression models were calculated between LGDs and topographic indices derived for $\mathrm{zi}_{25} \mathrm{~m}$ and $\mathrm{zi}_{50 \mathrm{~m}}$, as in these zones correlation between LGD and far-field conditions was strongest. Correlations between explanatory variables were checked and regarded as independent from each other if $\rho$ was below 0.7. Predictors were regarded as significant if $p$ values were below 0.05 . The goodness of fit of the models was estimated based on the coefficient of determination $\left(R^{2}\right)$.

\subsubsection{Groundwater flow field as control on large-scale LGD patterns}

The groundwater flow field was the second far-field variable assumed to affect the LGD patterns. The groundwater flow field is generally assumed to be largely controlled by topography. We used two approaches to test this assumption: the water table ratio (Haitjema and Mitchell-Bruker, 2005) and a comparative analysis of flow fields determined based on measured groundwater levels alone (ordinary kriging) or including topographic effects (regression kriging). The simple dimensionless water table ratio (WTR) is equal to $\left(R L^{2}\right) /(m k H d)$, with $R$ as the annual recharge rate $\left(\mathrm{md}^{-1}\right)$, $L$ as the mean distance between surface waters (m), $m=8$ or $16(-)$ for either 1-D or radial flow, $k$ as the average hydraulic conductivity $\left(\mathrm{md}^{-1}\right), H$ as the average aquifer thickness (m) and $d$ as the maximum terrain rise (m) (Haitjema and Mitchell-Bruker, 2005; Gleeson et al., 2011) allows a first test of the potential influence of topography on the groundwater flow field, with WTR greater than 1 indicating topography-controlled water tables and WTR less than 1 indicating recharge-controlled water tables. The average hydraulic conductivities were determined from 92 undisturbed cores taken during observation well installation and were measured in the lab using a permeameter.
In order to derive the groundwater flow field, measured groundwater heads from 16 observation wells located around Lake Hinnensee (Fig. 1a) were spatially interpolated. A total of 12 of the 16 bore wells were drilled in 2012, 3 were drilled in 2014 and 1 existed already before installation of the TERENO monitoring network. Groundwater levels were measured every 7-9 weeks since 2012 using an electric contact meter (SEBA Hydrometrie, electric contact meter type KLL, accuracy: $\pm 1 \mathrm{~cm}$ ). To determine the groundwater flow field, we used groundwater levels measured in 2014, when all wells were completed. In 2014, groundwater levels were generally lower than during the VTP measurement campaigns (2011-2013), but the spatial patterns of groundwater heads of the 12 wells already installed in 2012 remained stable. Groundwater levels from March 2014 had the smallest differences (mean difference $5.55 \mathrm{~cm}$ ) to available groundwater data around the time of the VTP measurement campaigns and were thus chosen to derive the groundwater flow field. For the interpolation of the groundwater measurements, we used both ordinary kriging and regression kriging. In regression kriging, a linear regression between an external variable and the depending variable is included. This allowed us to incorporate the potential effect of topography on the groundwater flow field. In order to minimize the effect of small-scale heterogeneities in the topography, the DEM was smoothed by reducing the resolution from 1 to $10 \mathrm{~m}$ and rescaling to a resolution of $1 \mathrm{~m}$ to maintain a consistent resolution of the results. The groundwater gradients were then calculated from the interpolated groundwater surface.

To analyse the correlation of the groundwater flow field with the LGD patterns, we averaged groundwater gradients in each of the subcatchments for each zone of influence (arithmetic mean) and correlated these with the median LGD rates of the subsections using Spearman's rank correlation coefficient as described in Sect. 2.3.2. In addition to the correlation analyses, simple linear regression models were calculated between LGD and groundwater gradients. Furthermore, groundwater gradients were also included in multiple linear regression models with topographic indices.

All analyses were carried out in the statistic software R (R Development Core Team, 2011). For the geographical analyses, we used the geographical information system SAGA GIS and the package "rsaga" (Brenning, 2008).

\section{Results}

\subsection{Estimating lacustrine groundwater discharge}

\subsubsection{Near-shore LGD derived from vertical temperature profiles}

At 216 locations along the shoreline of Lake Hinnensee (Fig. 1), a total of 520 VTPs were measured to analyse (a) spatial patterns of near-shore LGD, (b) the trend of LGD 
with increasing distance from the shore and (c) the temporal stability of LGD patterns. These 520 profiles thus include repeated measurements in time as well as measurements at two distances to the shore. At the western lake section, 150 to $290 \mathrm{~m}$ from the northern tip, VTP measurements could only be taken every $20 \mathrm{~m}$ instead of every $10 \mathrm{~m}$ as the lake shore could either not be accessed or the sediment was unsuitable for measuring due to a thick layer of muddy organic material. However, as lake sediments in this lake section were quite homogeneous, we assume that despite the wider spacing we still captured the spatial variability of LGD. The same reasons also precluded measurements at 11 other locations around the lake. These other 11 locations were irregularly distributed so that gaps were small and we do not expect a strong influence of these gaps on overall spatial patterns. A total of 22 profiles $(4 \%)$ were excluded from the analyses as no satisfying fit to the heat transport equation could be achieved. The quality of all remaining LGD estimations was satisfactory (median (RMSE) $=0.06^{\circ} \mathrm{C} ; n=498$ ).

\section{Spatial patterns along the shoreline}

LGD rates determined from VTPs every $10 \mathrm{~m}$ along $2.39 \mathrm{~km}$ of the shoreline (216 locations) ranged from $-12 \mathrm{~L} \mathrm{~m}^{-2} \mathrm{~d}^{-1}$ (losses) to $169 \mathrm{~L} \mathrm{~m}^{-2} \mathrm{~d}^{-1}$ (gains) with a median of $44 \mathrm{~L} \mathrm{~m}^{-2} \mathrm{~d}^{-1}$ and an interquartile range (IQR) of $26 \mathrm{~L} \mathrm{~m}^{-2} \mathrm{~d}^{-1}$. Occurrence of very strong LGD rates of more than $94 \mathrm{Lm}^{-2} \mathrm{~d}^{-1}$ (positive outliers of LGD distribution) was limited to the northernmost $140 \mathrm{~m}$ on both the western and eastern shores of the lake (between "a" and "b" and " $\mathrm{f}$ " and "g" in Fig. 2b and c) and to one single spot at the western shore $470 \mathrm{~m}$ to the south ("i" in Figs. 1 and 2c). The northernmost $140 \mathrm{~m}$ on both the western and eastern shores (between "a" and "b" and "f" and "g" in Figs. 1 and 2b, c) are in the following called "the northern part" and the adjacent region in the south (between "b" and "e" and " $g$ " and " $\mathrm{j}$ " in Figs. 1 and 2b) will be called "the southern part". Negative rates were only observed at the eastern shore between 480 and $530 \mathrm{~m}$ from the northern tip ("c" in Figs. 1 and 2b, c). In the northern part of the lake, LGD was stronger and spatially more variable (median of $74 \mathrm{~L} \mathrm{~m}^{-2} \mathrm{~d}^{-1}$ ) than in the southern part (median of $41 \mathrm{~L} \mathrm{~m}^{-2} \mathrm{~d}^{-1}$ ) (Figs. 2 and 3). In the northern part, LGD was statistically uncorrelated for all lag distances, while in the southern part it was autocorrelated up to a lag distance of $50 \mathrm{~m}$ with $|\rho|$ ranging between 0.62 and 0.23 (Fig. 3). Autocorrelation in the southern part was stronger on the eastern than on the western shore.

\section{Spatial patterns perpendicular to the shoreline}

Between 660 and $1520 \mathrm{~m}$ along the eastern shore and 300 and $830 \mathrm{~m}$ south of the northern tip along the western shore, VTPs were measured at 50 and $150 \mathrm{~cm}$ distance from the shoreline to analyse the trend of LGD with increasing distance from the shore.
In more than two-thirds of all cases (71\%), LGD measured at $150 \mathrm{~cm}$ from the shoreline was lower than the rate measured at $50 \mathrm{~cm}$ distance (Fig. 2). The reduction of LGD rate was on average $20 \%$ (median). However, in $29 \%$ of all cases, LGD increased with distance to the shore (Fig. 2) with an average increase of $15 \%$ (median). The patterns of LGD along the shoreline measured 50 and $150 \mathrm{~cm}$ apart from the shore were very similar $\left(\rho=0.81\right.$ ( $p$ value $\left.<2 \times 10^{-16}\right)$; Fig. 2$)$.

\section{Temporal stability of spatial patterns}

The annual repetitions of LGD rates measured at 43 VTP positions (Fig. 1) highlight that the observed LGD patterns were correlated between the individual measurement campaigns (Fig. 4). The correlation coefficient was 0.71 $\left(p\right.$ value $\left.=5 \times 10^{-6}\right)$ between summer 2011 and $2012(n=$ 34), $0.82\left(p\right.$ value $\left.=10^{-3}\right)$ between 2012 and summer 2013 $(n=13), 0.70\left(p\right.$ value $\left.<4 \times 10^{-6}\right)$ between 2012 and winter $2013(n=34)$, and $0.66\left(p\right.$ value $\left.<3 \times 10^{-5}\right)$ between 2011 and winter $2013(n=33)$. The differences between LGD rates measured in different years were lowest comparing rates from summer 2011 and summer 2012 (median of $-6 \mathrm{~L} \mathrm{~m}^{-2} \mathrm{~d}^{-1}$ ) and strongest comparing rates from summer 2011 and winter 2013 (median of $27 \mathrm{~L} \mathrm{~m}^{-2} \mathrm{~d}^{-1}$ ).

\section{Single sediment temperature measurements as a qualitative indicator for LGD spatial patterns}

Sediment temperatures from the top of the sediment down to a depth of $10 \mathrm{~cm}$ were not well correlated with LGD rates, but strong correlations were found between LGD rates and sediment temperatures measured $20 \mathrm{~cm}$ below the surface and deeper (correlation coefficients range between 0.46 and 0.96 ). While the correlation is generally high, the slope of the regression line varies in time (Fig. 5).

\subsubsection{Lake sediment temperature anomalies as indicators for LGD based on fibre-optic distributed temperature sensing (FO-DTS)}

We measured lake sediment temperature with a FO-DTS cable installed in six transects through the northern part of the lake (Fig. 1c) during two measurement campaigns (20 February and 27 August 2014) to identify offshore groundwater inflow. The complementary results of the radon measurement campaigns are described in Appendix A.

The winter and summer measurements consisted of 15 measurements in $2 \mathrm{~min}$ intervals. The repetitions resulted in very similar measurements (median range of temperature differences among repetitions in winter: $0.19^{\circ} \mathrm{C}$; maximum range in winter: $0.44^{\circ} \mathrm{C}$; median range in summer: $0.22^{\circ} \mathrm{C}$; maximum range in summer: $0.38^{\circ} \mathrm{C}$ ) (Fig. 6a). In winter, sediment temperature ranged between 3.4 and $5.3^{\circ} \mathrm{C}$, and in summer between 17.0 and $18.4^{\circ} \mathrm{C}$ (Fig. 6). In summer, groundwater was $7^{\circ} \mathrm{C}$ cooler than lake water and in winter $3^{\circ} \mathrm{C}$ warmer than the lake. The air temperature, groundwater 


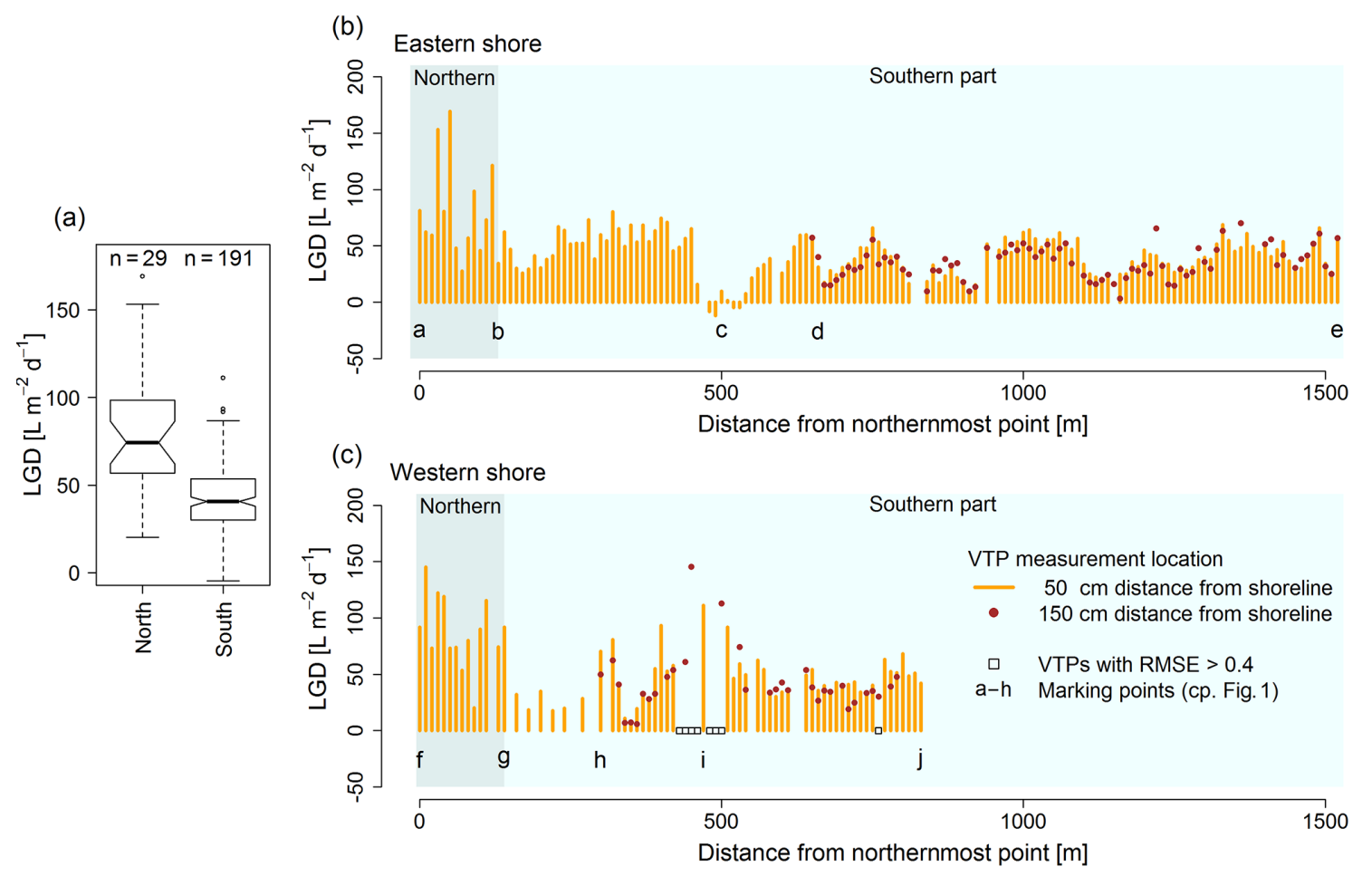

Figure 2. LGD estimated from VTPs measured at 50 and $150 \mathrm{~cm}$ distance from the shoreline: LGD distribution from VTPs in the northern and southern parts measured at a distance of $50 \mathrm{~cm}$ (a), LGD along the eastern shore (b) and LGD along the western shore (c). Locations where fits of the heat transport equation were poor (RMSE $>0.4)$ are indicted with squares.
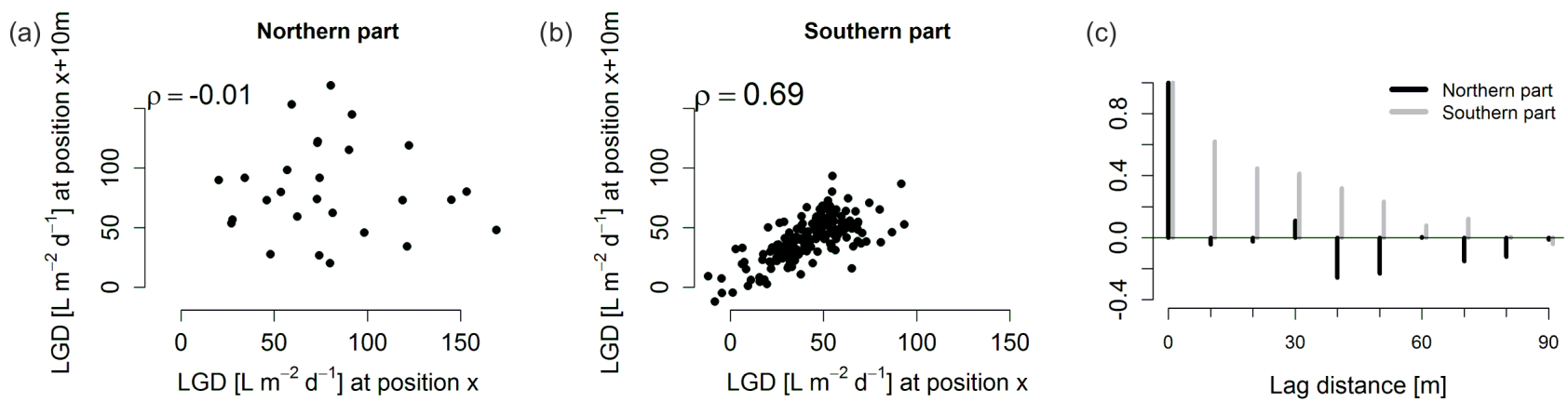

Figure 3. Correlation between neighbouring LGD measurement locations (distance $10 \mathrm{~m}$ ) in the northern part (a) and southern part (b); autocorrelogram for the LGD series of the northern and southern parts of the lake (c).

temperatures and temperature depth profiles of the lake measured during the DTS measurements are presented in Table 2.

The spatial patterns of sediment temperature anomalies, i.e. the shifts of sediment temperatures towards groundwater temperatures, were similar in both campaigns. Strongest deviations from sediment temperatures towards the groundwater temperatures (positive in winter and negative in summer) were located near the shoreline at corners 2 and 3 (Fig. 6). A slight shift towards groundwater temperatures was also observed near corner 5 but only along the DTS cable north of the corner. These hot and cold spots in winter and summer, respectively, were not located nearest to the shoreline but between 2 and $14 \mathrm{~m}$ offshore, where lake depth steeply increased (Fig. 6b).

\subsection{Identifying controls of LGD patterns}

\subsubsection{Sediment heterogeneity as a small-scale control}

\section{Hydraulic conductivity from slug tests}

The $k_{\text {sat }}$ values estimated from the slug tests ranged between $2.03 \times 10^{-6}$ and $4.25 \times 10^{-5} \mathrm{~ms}^{-1}$ with an IQR of $1.41 \times$ $10^{-5} \mathrm{~ms}^{-1}$ (Fig. 7). Points with $k_{\text {sat values lower than the }}$ $25 \%$ quartile $\left(9.20 \times 10^{-6} \mathrm{~ms}^{-1}\right)$ were mainly located at the 


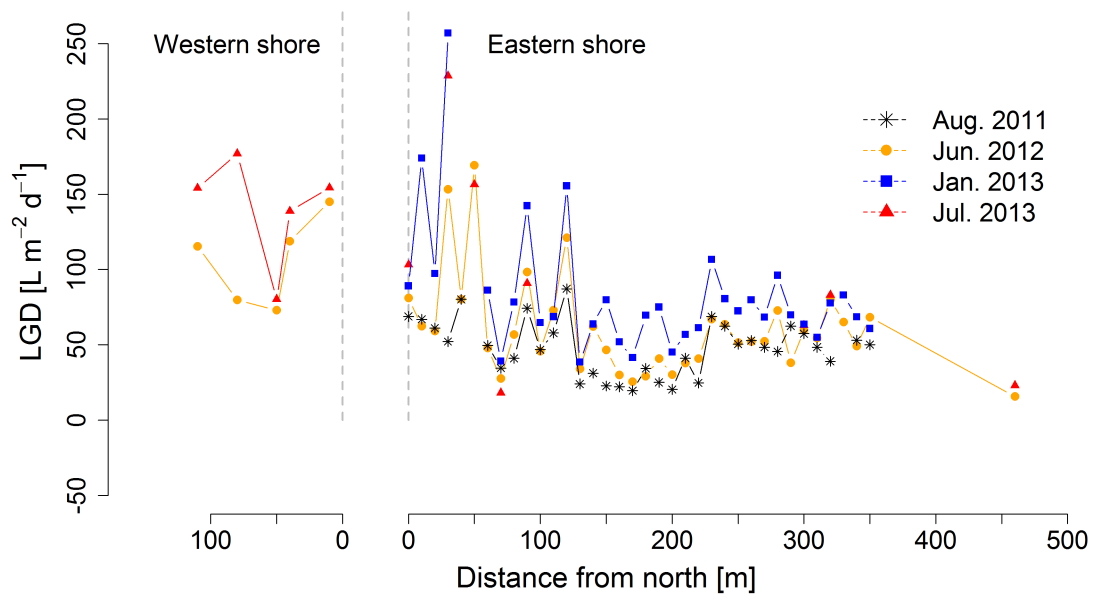

Figure 4. Calculated LGD rates from repetitions of VTP measurements in August 2011, June 2012 and January and July 2013 at the western and eastern shores in the northern part.

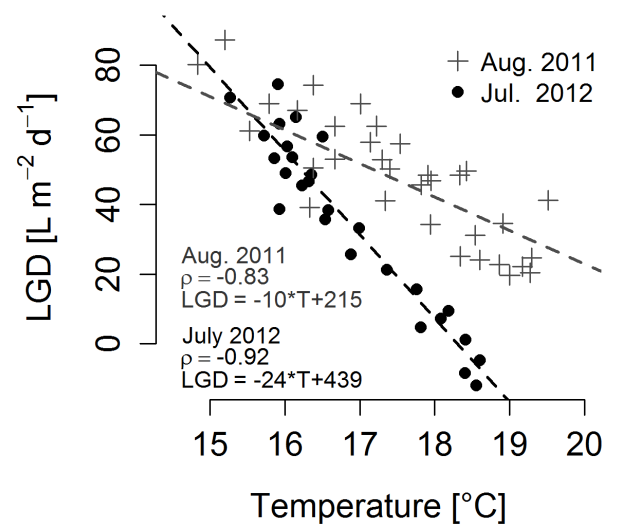

Figure 5. Sediment temperature measured $30 \mathrm{~cm}$ below the sediment lake interface during two different VTP surveys vs. LGD rates estimated from VTPs.

western shoreline, while points with values higher than the $75 \%$ quartile $\left(2.33 \times 10^{-5} \mathrm{~m} \mathrm{~s}^{-1}\right)$ were located on the eastern shore. Instead of a positive correlation between $k_{\text {sat }}$ values and LGD rates, there was a slight negative, but statistically insignificant ( $p$ value $=0.05$ ), correlation of -0.36 (Fig. 7).

\section{Grain size distributions from sediment cores}

The sediment samples taken from 30 VTP measurement locations were dominated by sand with a small fraction of gravel and silt. The median percentages of sand, gravel and silt were $92.3,6.8$ and $0.6 \%$, respectively. Within the sand fraction, medium sand dominated (median of $59.2 \%$ ), followed by fine sand (median of $23.3 \%$ ) and coarse sand (median of $13.7 \%$ ). No consistent layering or trends of grain sizes with depth could be identified. Only the fraction of medium sand decreased slightly with increasing sampling depth by $2 \%$ every $10 \mathrm{~cm}$, but also here the correlation was weak $\left(\rho=0.3, p\right.$ value $\left.=6 \times 10^{-4}\right)$.

Relating grain size distributions averaged over the upper metre of the lake sediment to the strength of LGD showed that low LGD rates occurred at locations dominated by fine sand and stronger LGD rates occurred at locations with a higher fraction of larger grain sizes (Fig. 8a). LGD was positively correlated with the percentage of gravel and coarse sand and negatively correlated with the percentage of fine sand (Table 3, Fig. 8b-c), but LGD rates were uncorrelated with the grain size fractions of medium sand and silt (Table 3). LGD varied by a factor of 3 across these grain size fractions. For the multiple regression model, considering all grain sizes, only coarse sand and fine sand were significant variables ( $p$ values $<0.05$ ). The model had an $R^{2}$ of 0.54 (Table 3 ). The absolute residuals were on average $21 \mathrm{~L} \mathrm{~m}^{-2} \mathrm{~d}^{-1}$, with largest positive residuals (observed less than calculated) at distances of 50 and $10 \mathrm{~m}$ from the northern tip at the eastern and western shores, respectively, and largest positive residuals (observed greater than calculated) at distances of 70 and $90 \mathrm{~m}$ from the northern tip at the eastern shore (Fig. 9a).

\subsubsection{Topographic indices as controls on large-scale LGD patterns}

Subcatchments derived from the 46 shoreline sections differed significantly in size. While subcatchments in the flatter areas of the south were larger, elevations were higher and slopes generally steeper in the north. There was no clear correlation between LGD rates and the size of the subcatchment in each topographical zone of influence (Table 4). Percentages of area with low topographic gradient in direct vicinity of the lake shore area were also not correlated with LGD rates, except for $\mathrm{zi}_{25} \mathrm{~m}$, where a weak negative correlation was found (Table 4). The correlation between LGD rates and 
(a)

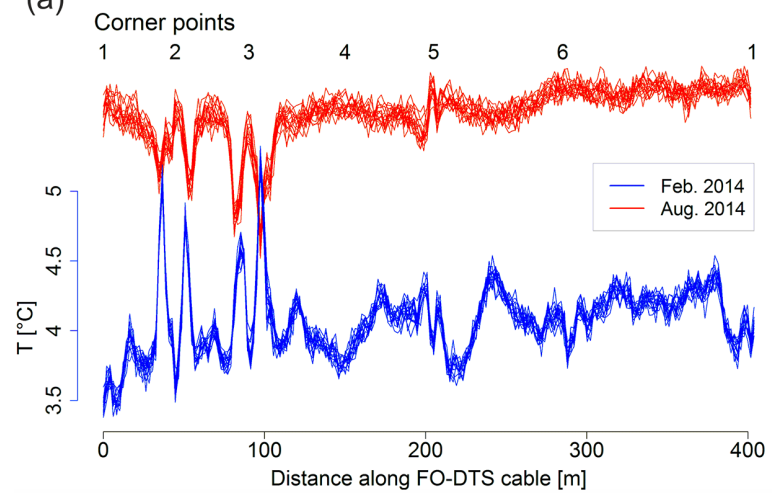

(b)

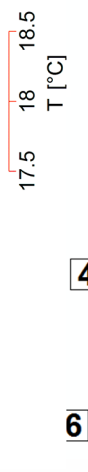

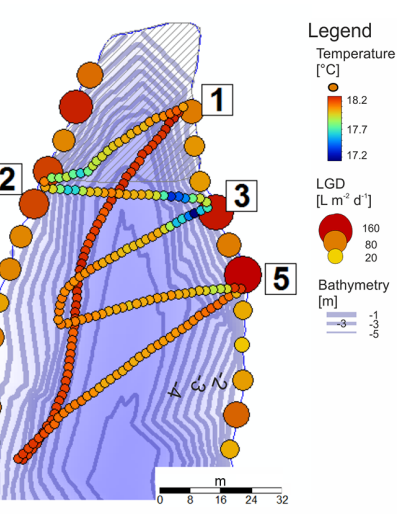

Figure 6. Lake sediment temperatures measured with the FO-DTS system. (a) Temperatures measured in February and August along the FO-DTS cable. (b) Sediment temperatures measured with the FO-DTS in August 2014 (median); LGD rates along the shoreline were derived from VTPs measured in June 2012.

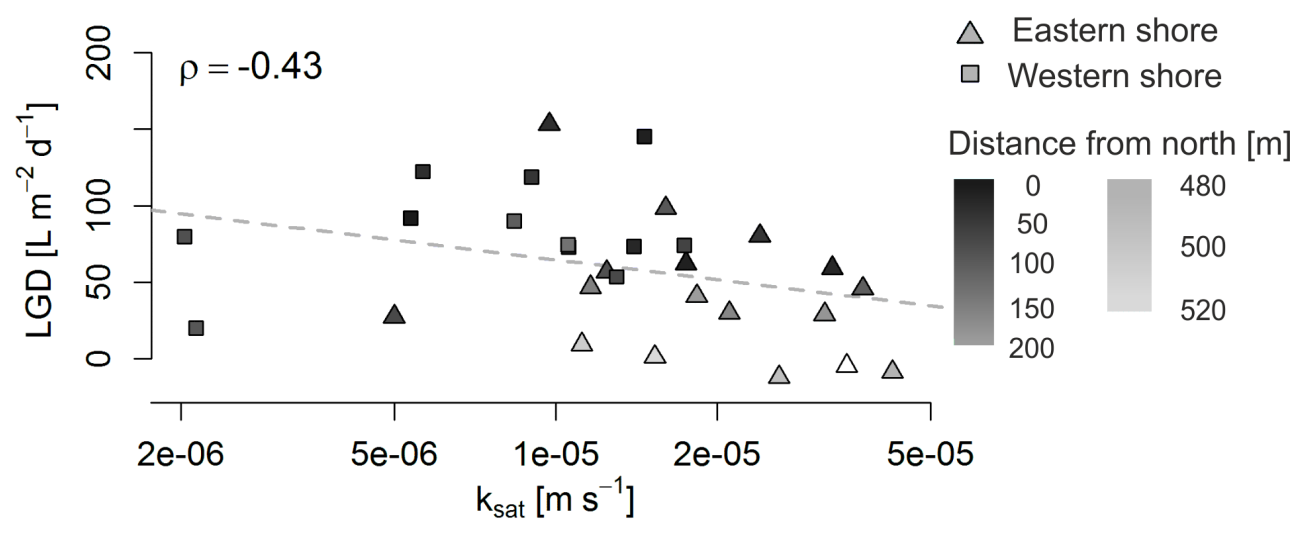

Figure 7. LGD plotted against $k_{\text {sat }}$ values determined from slug tests at the western and eastern shores; the grey shading indicates the distances of measurement locations from the northern tip of the lake.

Table 3. Correlation coefficients $(\rho)$, linear models describing the correlation between LGD and predictors and the coefficient of determination $\left(R^{2}\right) . \rho$ values given in boldface indicate significant correlation ( $p$ value $>0.05$ ); normal typeface values indicate insignificant correlations ( $p$ value $<0.05$ ).

\begin{tabular}{lrrr}
\hline Predictor $(x)$ & $\rho$ & Models (LGD $=\ldots$ ) & $R^{2}$ \\
\hline Gravel & $\mathbf{0 . 6 1}$ & $49.84+1.78 x$ & 0.25 \\
Coarse sand & $\mathbf{0 . 6 2}$ & $14.03+5.27 x$ & 0.46 \\
Medium sand & 0.01 & - & - \\
Fine sand & $\mathbf{- 0 . 7}$ & $127-2.12 x$ & 0.48 \\
Silt & 0.01 & - & - \\
Coarse plus fine sand & & $72.72+3.06 x_{1}-1.35 x_{2}$ & 0.54 \\
\hline
\end{tabular}

the indices' elevation and slope were both positive (Table 4, Fig. 10b and c) and the strength of correlation was strongest for $\mathrm{zi}_{50 \mathrm{~m}}$ and decreased with increasing zone of influence (Table 4).

\subsubsection{Groundwater flow field as control on large-scale LGD patterns}

The water table ratio (Haitjema and Mitchell-Bruker, 2005) as an indicator for either recharge- or topography-controlled groundwater tables was determined based on conservative estimates of the input variables: annual recharge rate $R=$ $0.00351 \mathrm{~m} \mathrm{~d}^{-1}$ (based on values from Müller et al., $2009 \mathrm{de}-$ termined in the same region), mean distance to the next surface waters $L$ being approximately $2000 \mathrm{~m}, m=8$ (-) for 1 $\mathrm{D}$ flow (however, changing this to 16 for radial flow does not change the outcome), the average hydraulic conductivity $k=7.776 \mathrm{md}^{-1}$ (based on laboratory analyses of undisturbed cores obtained during observation well installation), average aquifer thickness $H=15 \mathrm{~m}$ (from bore logs) and the maximum terrain rise $d=52 \mathrm{~m}$. The water table ratio in this case amounts to 0.029 which is $\ll 1$ and thus indicates that water tables in the study area are not topography controlled but instead recharge controlled.

The interpolated groundwater table based on the water tables in the observation wells showed groundwater flow to- 
(a)

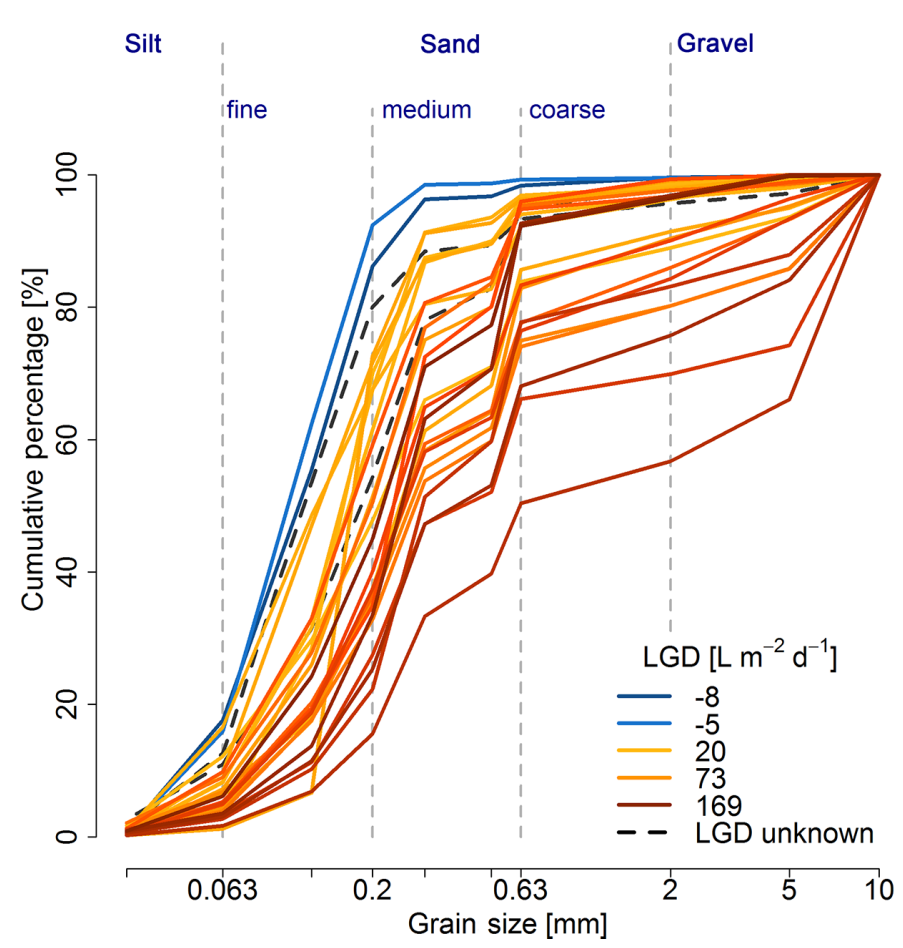

(b)

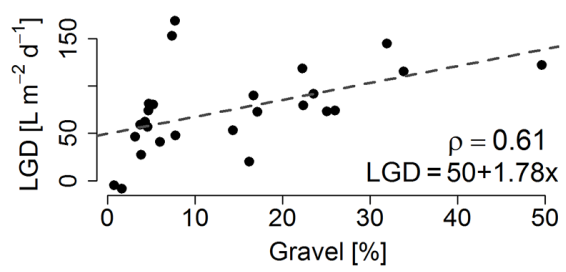

(c)

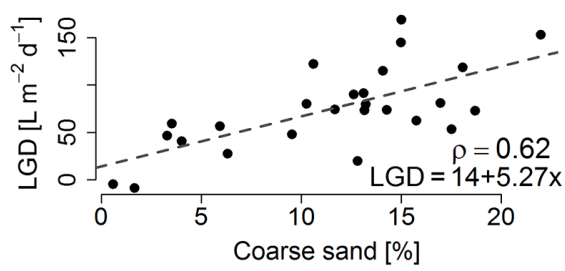

(d)

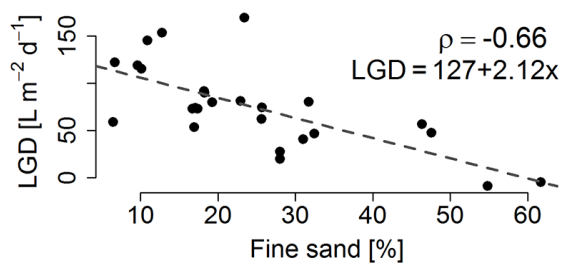

Figure 8. (a) Grain size distributions averaged over the upper metre of the lake sediment from sediment cores coloured by the strength of LGD rate; LGD rates are plotted against the grain sizes for gravel (b), coarse sand (c) and fine sand (d).
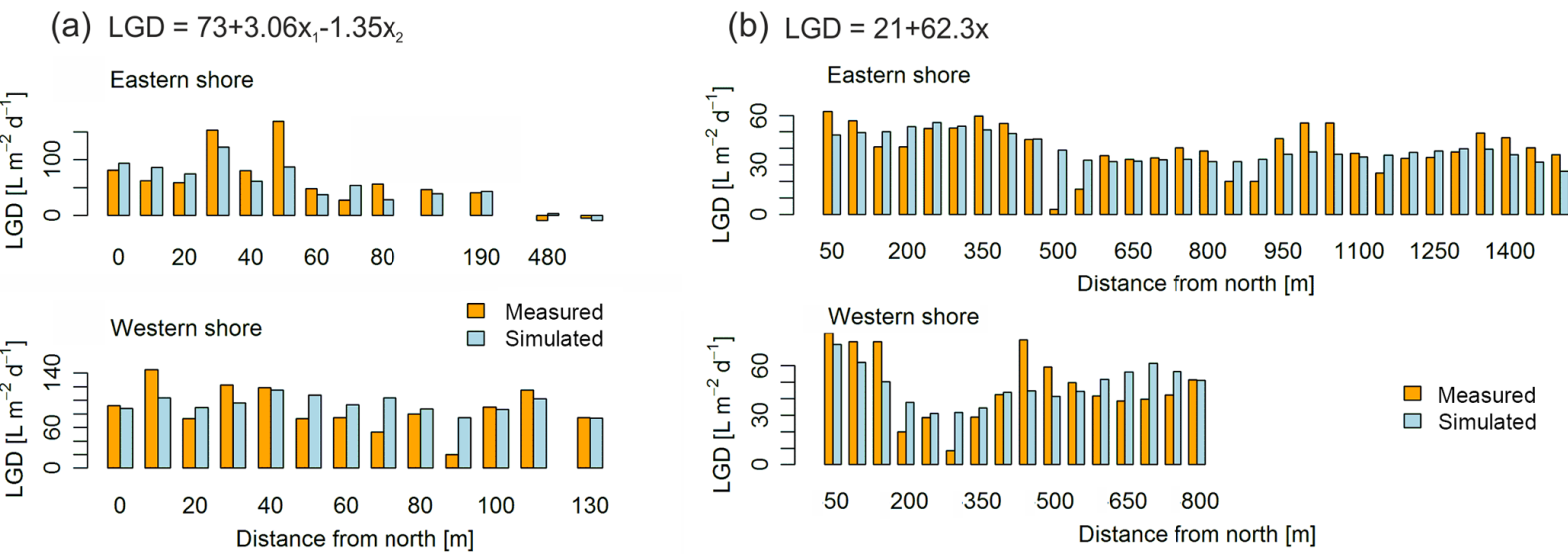

Figure 9. Observed and calculated LGD distribution along the shoreline. (a) Small-scale patterns predicted using a multiple regression model with coarse sand and fine sand as predictors and (b) large-scale patterns predicted by the linear model based on groundwater gradients derived from regression kriging from zone $\mathrm{zi}_{25} \mathrm{~m}$. Regression equations for both small- and large-scale patterns are included in the upper right corner. In the small-scale variability equation, $x_{1}$ stands for the fraction of coarse sand and $x_{2}$ for fine sand.

wards Lake Hinnensee from all directions (Fig. 10). In general, groundwater gradients were stronger in the north than in the south.

The maximum deviation between interpolated and measured groundwater levels was below $1 \mathrm{~cm}$ for both interpolations, but in comparison to the ordinary kriging, the regression kriging (which included topographical information) re- sulted in significantly stronger gradients: median groundwater gradient in the $\mathrm{zi}_{200 \mathrm{~m}}$, for example, was $0.24 \mathrm{~cm} \mathrm{~m}^{-1}$ using regression kriging and $0.09 \mathrm{~cm} \mathrm{~m}^{-1}$ using ordinary kriging. While the correlation between LGD and groundwater gradients derived from ordinary kriging was weak, with correlation coefficients ranging between 0.28 and 0.37 (Table 2), stronger correlation was found for LGD and gradients de- 

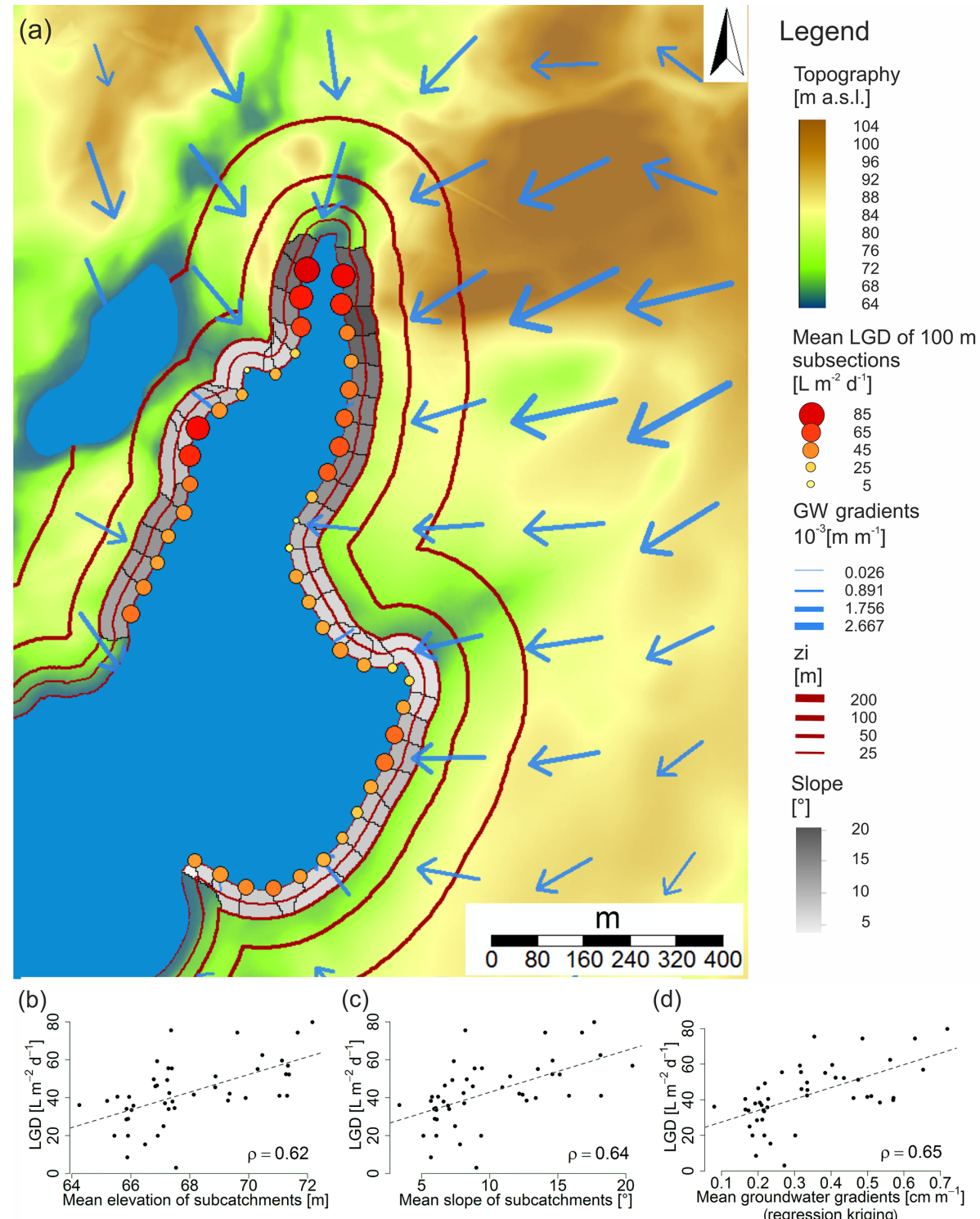

Figure 10. Correlation between far-field conditions and LGD. (a) LGD of lake subsections and mean slope of upslope areas for topographical zone of influence (zi) of $50 \mathrm{~m}$; groundwater gradients ( $\mathrm{GW}$ gradients) are derived from interpolation of measured groundwater levels using regression kriging. (b-d) LGD rates of lake subsections are plotted against the far-field conditions' mean elevation (b), mean slope (c) and mean groundwater gradients derived from regression kriging $(\mathbf{d})$ calculated for $\mathrm{zi}_{50 \mathrm{~m}}$.

Table 4. Correlation coefficients $(\rho)$ between LGD and far-field predictors calculated for upslope areas in certain topographical zones of influence (zi). $\rho$ values in italic indicate insignificant coefficients ( $p$ value $>0.05$ ). $\rho$ values in bold indicate strong significant coefficients ( $p$ value $<0.05$ ). gg is the abbreviation for groundwater gradients and ltg the abbreviation for low topographic gradient in direct proximity to the lake shore.

\begin{tabular}{lrrrrrr}
\hline Predictors/zi & Size & Mean elevation & Mean slope & Percentage of ltg & $\begin{array}{r}\text { Mean gg } \\
\text { (ordinary kriging) }\end{array}$ & $\begin{array}{r}\text { Mean gg } \\
\text { (regression kriging) }\end{array}$ \\
\hline $25 \mathrm{~m}$ & 0.15 & $\mathbf{0 . 6 1}$ & $\mathbf{0 . 5 8}$ & -0.44 & 0.33 & $\mathbf{0 . 6 4}$ \\
$50 \mathrm{~m}$ & 0.03 & $\mathbf{0 . 6 2}$ & $\mathbf{0 . 6 4}$ & -0.30 & 0.36 & $\mathbf{0 . 6 5}$ \\
$100 \mathrm{~m}$ & -0.19 & 0.45 & $\mathbf{0 . 5 8}$ & 0.00 & 0.32 & $\mathbf{0 . 5 9}$ \\
$200 \mathrm{~m}$ & -0.31 & 0.23 & $\mathbf{0 . 5 4}$ & -0.02 & 0.33 & $\mathbf{0 . 5 5}$ \\
\hline
\end{tabular}


rived from regression kriging (between 0.55 and 0.64) (Table 2). The linear predictor function used for the regression kriging was $\mathrm{gw}=62.5+0.02 e$ where $\mathrm{gw}$ is the groundwater level in metres and $e$ the smoothed surface elevation in metres. The topography was a significant model predictor with a $p$ value of $10^{-5}$.

\subsubsection{Linear regression models between LGD and far-field predictors}

The linear regression models describing the correlation between LGD and far-field conditions were estimated for all predictors of $\mathrm{zi}_{25 \mathrm{~m}}$ and $\mathrm{zi}_{50 \mathrm{~m}}$. Significant predictors of LGD large-scale patterns were elevation, slope, percentage of area with low topographic gradient (only in $\mathrm{zi}_{25} \mathrm{~m}$ ) and groundwater gradients (Table 5). No significant linear regression model was found with the potential predictors "potential size of subcatchment" and "percentage of area with low topographic gradient" in $\mathrm{zi}_{50 \mathrm{~m}}$. The $R^{2}$ values of all models were not larger than 0.37 (Table 5) but were below 0.12 for the "percentage of area with low topographic gradient" and "groundwater gradients derived from ordinary kriging" predictors (Table 5). Therefore, these predictors were excluded for further analyses.

The calculation of multiple regression models revealed no significant relations between LGD and topographic indices in both zones of influence. Stepwise reduction of the most insignificant predictor until all predictors became significant resulted in the single linear regression models as presented above and in Table 5.

Calculated large-scale LGD patterns along the shoreline using the best linear regression model (based on groundwater gradients derived from regression kriging in $\mathrm{zi}_{25} \mathrm{~m}$; Table 5) are shown in Fig. 9b. The general spatial pattern was captured by the model, but absolute deviations were on average $10.4 \mathrm{~L} \mathrm{~m}^{-2} \mathrm{~d}^{-1}$. Strongest overestimations occurred at distances of $500 \mathrm{~m}$ at the eastern and $300 \mathrm{~m}$ at the western shore and strongest underestimation by the model were found at distances of 450 and $150 \mathrm{~m}$ at the western shore.

\section{Discussion}

\subsection{LGD patterns along the shoreline and potential controls}

The experimental design based on extensive field campaigns employed here provided exceptionally detailed information on both small-scale variabilities and large-scale patterns of LGD rates along a lake shoreline. This data set thus bridges the gap between the detailed local and low-resolution largerscale investigations of previous LGD studies.

While the employed method of measuring VTPs with a needle thermistor is sufficiently rapid to make this large high-resolution data set possible, it nevertheless takes considerable effort. We therefore investigated if measuring tem- perature at just a single depth instead of measuring an entire depth profile (thus reducing measurement time even further) would already supply at least qualitative information on LGD patterns. We found that temperatures measured at depths larger than $20 \mathrm{~cm}$ generally correlated well with LGD rates, thus reproducing the general pattern of groundwater inflow. However, to convert these temperatures to LGD rates it would be necessary to measure at least some complete profiles for a large enough range of LGD rates to obtain a decent calibration. As sediment temperatures and their gradients change over time, this calibration needs to be repeated at each survey date.

\subsubsection{Large-scale patterns}

As expected, the observed large-scale patterns of LGD at Lake Hinnensee correlated with mean groundwater gradients. Interestingly, even though the system classifies as recharge controlled and not topography controlled according to the water table ratio (Haitjema and Mitchell-Bruker, 2005; Gleeson et al., 2011), correlation was stronger between LGD and groundwater gradients derived from regression kriging (which includes topographic information) than between LGD and groundwater gradients derived from ordinary kriging. This suggests that the groundwater surface was more realistically interpolated using regression kriging and indicates at least some influence of topography on groundwater movement, which is consistent with the theory of topography-controlled groundwater flow described by Toth (1963). The predictors based on surface slopes and surface elevation, hence purely topographical information, also correlated with LGD rates (with a correlation coefficient of 0.6) - another indication of at least some topographic control on the groundwater flow field. However, even the best regression model (based on the groundwater table gradients from regression kriging) did not capture all of the observed variability in LGD, thus suggesting the existence of additional controls. In contrast to observations of streamflow generation in mountain catchments (Jencso et al., 2009, 2010), no positive correlation was found between the size of the subcatchment and LGD rates (Table 4), indicating that surface catchments derived for lake subsections were not a good estimator for the amount of subsurface water flowing into the corresponding lake sections. We assume our result indicates that subsurface catchments differ from surface catchments which is not unusual in lowland areas. The weak negative correlation between LGD and the topographic index "percentage of area with low topographic gradient in direct vicinity of the lake shore" in $\mathrm{zi}_{25} \mathrm{~m}$ indicated that low topographic gradients at the shoreline could buffer groundwater flow towards the lake.

Even though the interpolated groundwater surface showed groundwater flow towards Lake Hinnensee from all directions (Fig. 10), we measured negative LGD rates at one small subsection of the lake (Fig. 2). Reasons for this flow re- 
Table 5. Linear regression models describing the correlation between LGD and far-field predictors and the coefficient of determination $\left(R^{2}\right)$. $\mathrm{gg}$ is the abbreviation for groundwater gradients and ltg the abbreviation for low topographic gradient in direct proximity to the lake shore.

\begin{tabular}{|c|c|c|c|c|}
\hline Predictor $(x)$ & $\begin{array}{l}\mathrm{zi}_{25 \mathrm{~m}} \\
\text { Models }(\mathrm{LGD}=\ldots)\end{array}$ & $R^{2}$ & $\begin{array}{l}\mathrm{zi}_{50 \mathrm{~m}} \\
\text { Models }(\mathrm{LGD}=\ldots)\end{array}$ & $R^{2}$ \\
\hline Elevation & $-591.62+9.65 x$ & 0.35 & $-273.14+4.65$ & 0.34 \\
\hline Slope & $21.66+2.04 x$ & 0.33 & $20.74+2.2 x$ & 0.32 \\
\hline Percentage of ltg & $52.61-1.29 x$ & 0.11 & - & - \\
\hline Ordinary kriging (gg) & $30.12+141.11 x$ & 0.09 & $27.18+167.90 x$ & 0.12 \\
\hline Regression kriging (gg) & $21.16+62.30 x$ & 0.37 & $21.08+64.36 x$ & 0.36 \\
\hline
\end{tabular}

versal are unclear. However, the neighbouring stretches of shoreline were characterized by very low LGD rates (Fig. 2), even though $k_{\text {sat }}$ values at this section were comparably high (Fig. 7), and thus we assume that very low hydraulic gradients are the cause for the low LGD rates. While transpiration is likely to cause diurnal fluctuations in groundwater levels all around the lake, it can result in a temporary local inversion of the groundwater-lake gradients at locations where these gradients are very low (Winter et al., 1998). This could be a potential explanation for the negative LGD rates measured at this location.

\subsubsection{Small-scale patterns}

Our measurements revealed strong small-scale spatial variability in LGD along the shoreline (Fig. 2). Absolute amounts and spatial variability of LGD were within the range of previous studies (Rosenberry et al., 2015; Blume et al.; 2013; Neumann et al., 2013). Measuring VTPs with a high measurement resolution along large parts of the shoreline highlighted furthermore that the strength of small-scale variability also varies along the shoreline. This type of information is likely to be overlooked in studies focusing either on entire lake systems but using a low spatial resolution (Schneider et al., 2005; Meinikmann et al., 2013; Shaw et al., 2013) or using a high spatial resolution but only on a very local scale (Kishel and Gerla, 2002; Blume et al.; 2013; Sebok et al., 2013). The repetitions of VTP measurements revealed that the observed patterns were stable in time and are thus likely controlled by static characteristics. Differences in LGD rates measured in different years are likely the result of annual differences in groundwater recharge and thus gradients of the flow field.

Surprisingly, no positive correlation was found between LGD rates and $k_{\text {sat }}$ values derived from slug tests at Lake Hinnensee. The relationship between $k_{\text {sat }}$ and LGD could be confounded as a result of strong differences in hydraulic gradients. However, even when only adjacent measurement locations with similar gradients were taken into account, no clear positive correlations appeared (Fig. 7). Slug tests were found to be the most accurate method to determine $k_{\text {sat }}$ values of sandy stream beds (Landon et al., 2001), but estimation of hydraulic conductivity is always subject to high uncertain- ties (Landon et al., 2001; Kalbus et al., 2006). Even though the slug tests were carried out carefully, we cannot exclude that pore structure was altered during the piezometer installation, and thus the $k_{\text {sat }}$ values of lake sediments were changed. In contrast to $k_{\text {sat }}$ values, LGD rates clearly correlated with both the finest and the coarsest grain size fractions. Grain sizes give no direct information on hydraulic conductivity, but coarse sand and gravel are associated with higher hydraulic conductivity values than well-sorted fine sand (Bear, 1972). As LGD rates correlated positively with percentages of gravel and coarse sand and negatively with the percentage of fine sand, this corroborated the assumption that sediment heterogeneities do at least partially control small-scale variability in LGD. We furthermore see that a variation of LGD of up to a factor of 3 can be due to grain size variability alone.

\subsection{LGD patterns with increasing distance to the shore and their potential controls}

To identify LGD patterns with increasing distance to the shore, we analysed VTP profiles measured in 50 and $150 \mathrm{~cm}$ distances from the shoreline in the southern part. Results showed a prevailing decrease of LGD with distance to the shore. This observation corresponds to the theoretical pattern of LGD found by McBride and Pfannkuch (1975) and other experimental studies (Brock et al., 1982; Cherkauer and Nader, 1989; Kishel and Gerla, 2002; Blume et al.; 2013). The study from Blume et al. (2013), conducted at a small shoreline section of $20 \mathrm{~m}$ length and $4 \mathrm{~m}$ width in the northern part of Lake Hinnensee, indicated that the strongest decrease of LGD occurred in the first $1.5 \mathrm{~m}$ from the shore. However, LGD increased with increasing distance from the shore in $29 \%$ of the locations. The locations with anomalously increasing LGDs did not show any obvious anomalies with respect to local bathymetry, density of vegetation or organic top layers, which could have been used to explain the observed patterns. The hypothesis that differences in sediment characteristics cause these anomalies could unfortunately not be tested as no information on sediment characteristics is available for distances from the shore larger than $50 \mathrm{~cm}$. 


\subsection{Offshore-LGD patterns and potential controls}

We investigated the presence and absence of offshore LGD with two natural tracers (radon and heat), and the two methods led to similar results (for the radon results and discussion, see Appendix A). The FO-DTS measurements showed no shifts in sediment temperatures towards the groundwater temperature in the flatter and deeper parts of the lake (Fig. 6b), and we assume that groundwater inflow is insignificant here. Low radon activities measured offshore at the lake bottom across the entire lake also support this assumption (see Appendix A). Insignificant groundwater inflow in the flatter and deeper part of the lake is in correspondence with the theory of exponentially decreasing groundwater inflow with distance from the shore introduced by McBride and Pfannkuch (1975). Furthermore, we know from observations by divers that the lake bottom was covered with finegrained organic sediments, which typically accumulate in the deep, flat parts, where wave action cannot resuspend the fine sediments (Rosenberry et al., 2015). A layer of fine-grained sediment could significantly decrease hydraulic conductivity of the lake bed sediment and can even totally prevent groundwater-lake exchange (Kidmose et al., 2013).

FO-DTS showed local hotspots of groundwater inflow at three locations, all on steep steps between the near-shore part and the flatter central basin. These locations with sediment temperature anomalies coincided with high near-shore LGD rates (estimated with VTPs), while corners where no temperature anomalies were found coincided with low near-shore LGD rates (Fig. 6b). As hotspots in near-shore LGD occurred locally and mainly in the northern part of the lake, we assume that the occurrence of hotspots of LGD at steep steps is also a local phenomenon limited to the northern part. As the occurrence of the local sediment temperature anomalies is temporally stable (Fig. 6a), we assume that static characteristics are responsible - at these locations, where nearshore LGD was already strong, the morphology of steep steps might force a local offshore increase of LGD: at steep slopes, fine sediment is prone to be re-disturbed by turbidity current activities (Håkanson, 1977), locally increasing hydraulic conductivity and thus also LGD.

\subsection{Prediction of LGD patterns}

Using linear regression models based on topographic characteristics or the groundwater flow field to predict large-scale patterns of LGD at Lake Hinnensee roughly reproduced the observed patterns but locally strongly over- or underestimated the observed LGD rates (Fig. 9b). However, regression models considering sediment heterogeneities were able to explain more than $50 \%$ of the observed small-scale variability in LGD $\left(R^{2}=0.55\right)$. We calculated linear regression models separately for topographic indices and sediment heterogeneities, because sediment cores were only taken from a fraction of the lake, covering not more than one lake sub- section used for far-field analysis. But as LGD is driven by both the hydraulic gradients between lake and aquifer and the hydraulic conductivity, combining the information would likely explain more of the observed variability. Another possible influence is currently unknown local heterogeneous features within the adjoining aquifer (Winter, 1999; Cherkauer and Nader, 1989; Fleckenstein et al., 2009). Such smallscale structures may influence the groundwater flow paths and cause variability in LGD.

\section{Summary and conclusion}

As LGD can significantly contribute to lake water budgets and could furthermore significantly influence lake water quality by transporting large loads of nutrients or contaminants, quantifying LGD rates and determining LGD patterns can be essential for a sustainable lake management (Meinikmann et al., 2013; Lewandowski et al., 2015). While LGD is known to be spatially variable, it is also not easily measured, especially with an extent and spatial resolution that allows for the characterization of LGD patterns. Furthermore, causes and controls of these patterns are not well understood. Our aim was the characterization of LGD patterns at Lake Hinnensee based on a unique high-resolution data set that extends along most of the shoreline, and the use of this data set to test common assumptions that spatial patterns of LGD are controlled by sediment characteristics and the groundwater flow field, and the potential of topographic indices as a proxy for gradients of the groundwater flow field. Identifying external (and easily measurable) controls as a means for pattern prediction would greatly reduce experimental effort. By using VTPs in the near-shore area and FO-DTS measurements and radon sampling in the offshore area, we identified the following pattern in LGD for Lake Hinnensee: LGD was concentrated in the near-shore area and generally decreased with distance to the shore; some local hotspots of LGD were identified in locations of steep steps towards the lake bottom; overall, offshore LGD was insignificant. LGD was generally stronger and more variable in the northern part than in the southern part of the lake. Repetitions of LGD measurements indicated that the observed patterns in LGD remained stable in time. As the hydrogeology of the catchment is sufficiently homogeneous to avoid patterns being dominated by geological discontinuities, we were able to test the common assumptions that spatial patterns of LGD are controlled by sediment characteristics and the groundwater flow field (here interpolated from observation wells) and the potential of topographic indices as proxies for gradients of the groundwater flow field. We identified the following links between LGD patterns and external factors at Lake Hinnensee: even though they were classified not as topography controlled but as recharge controlled based on the water table ratio, large-scale LGD patterns were linked to the local topographic gradient and also to groundwater gradients 
derived from regression kriging, which also included topographic information. The explanatory power of these indices was strongest when derived locally up to a distance of $50 \mathrm{~m}$ from the shoreline, and decreased with increasing distance from the lake. Small-scale LGD patterns in the north were linked to sediment heterogeneities: LGD patterns correlated positively with percentages of gravel and coarse sand and negatively with the percentage of fine sand. However, LGD patterns did not correlate with $k_{\text {sat }}$ values derived from slug tests. We assume that our findings are transferrable to similar lowland landscapes with quasi-homogeneous aquifers. As the water table ratio at this site indicated recharge control, we assume topography to have an even greater influence on LGD patterns in areas where groundwater tables are classified as topography controlled. However, more complex hydrogeological settings which include discontinuities can override and mask the topographic signal.

Our results furthermore showed that predictions of LGD rates using regression models derived from correlation with external controls were associated with high uncertainties but nevertheless allowed a rough estimation of LGD patterns. Topographic indices, such as elevation or slope, are often readily available. Analysing grain size distributions of lake sediment is labour intensive, but sediment cores taken with transparent sampling tubes can be easily analysed at least qualitatively. This information combined with information of topographic gradients can then be used to develop an effective and efficient measurement design for more a detailed characterization of spatial patterns of LGD that goes beyond the rough estimate that the linear regression models can provide.

Measuring VTPs with a $45 \mathrm{~cm}$ long needle thermometer is a fast and inexpensive method to determine LGD rates without disturbing the sediment. Correlation between LGD rates and temperature values measured at $30 \mathrm{~cm}$ depth also show that even single depth temperature measurements can provide at least some rough qualitative information on LGD patterns. While installing a fibre-optic cable along the shoreline would have the advantage of providing a large high-resolution spatial data set as well as continuous measurements, the cable would need to be installed at a fixed depth $>20 \mathrm{~cm}$ to provide reliable data, uninfluenced by solar radiation and boundary effects. Such an installation of a kilometre-long cable at a fixed depth is challenging and would significantly disturb the sediment, potentially causing preferential flow paths and changing the very fluxes we want to measure. We therefore favour the manual measurements using the thermistor needle, as this method has furthermore the added advantage of providing temperature profiles and thus enabling us to obtain reliable quantitative estimates of LGD rates at a large number of locations.
From the experience gained in this study, we would suggest the following protocol for future studies of LGD patterns and controls:

1. Determine topographic indices for the $50 \mathrm{~m}$ region around the lake (broken down in partially overlapping subsections of a length representative of the variability in topography - in our study $100 \mathrm{~m}$ with $50 \mathrm{~m}$ overlap) and combine this with groundwater flow field information from observation wells. Determine if system classifies as groundwater or topography controlled by using the water table ratio, if only limited well information exists, to get a better idea of the groundwater table characteristics.

2. Predict LGD patterns based on this information.

3. Test predictions at eight locations (more if feasible) by measuring VTPs and estimating LGD rates based on the heat transport equation. If possible, perform additional single depth temperature measurements and compare the obtained qualitative LGD patterns with the ones predicted from topographic indices to further evaluate the reliability of the prediction.

4. Characterize small-scale variability at two of these locations (covering high and low inflow regions) by additional measurements at higher spatial resolution.

5. Use clear plastic tubes to sample sediment cores for quick visual inspection and rough classification according to grain size/permeability and relate this to the corresponding LGD at each of these locations.

6. If interested in the temporal stability of the LGD patterns, repeat step 3 at different points in time.

Data availability. Data are available from the authors on request. 
Appendix A: Identification of offshore lacustrine groundwater discharge based on radon concentrations

\section{A1 Background}

Radon $\left({ }^{222} \mathrm{Rn}\right)$ is produced within the natural decay chain of uranium and has a half-life of 3.82 days. Radon occurs naturally in the aquifer matrix and, as it is soluble, groundwater is enriched in radon as it passes through the aquifer matrix. However, once radon-enriched groundwater is in contact with air, radon degasses quickly. Consequently, radon activities in surface water are low. Due to the pronounced differences between groundwater and surface water concentrations, elevated radon activities can be used as an indicator for groundwater inflows as shown, for example, by Kluge et al. (2012), Ono et al. (2012) and Shaw et al. (2013).

\section{A2 Method}

In this study, we used radon as a qualitative indicator of presence or absence of offshore LGD. We took water samples of 1.5 or $1.75 \mathrm{~L}$ from the bottom of the lake (lower end of the water column) at 19 locations (Fig. A1a) during three campaigns: 5 June 2013 (seven southernmost samples), 17 September 2013 (eight samples) and 21 August 2014 (three samples along the FO-DTS cable close to corner 2; Fig. A1b). Water samples taken at along the cable were taken by divers. All other samples were taken from a boat using a peristaltic pump. Contact between water samples and air was minimized and bottles were filled without air bubbles. To test the reliability of radon concentrations to identify groundwater inflow at Lake Hinnensee, we took water samples from two near-shore VTP locations where LGD rates were known and significantly different: one with strong inflow $\left(153 \mathrm{~L} \mathrm{~m}^{-2} \mathrm{~d}^{-1}\right.$, located $40 \mathrm{~m}$ south from the northernmost VTP measurement location at the eastern shore; Fig. A1b) and one with medium inflow $\left(48 \mathrm{~L} \mathrm{~m}^{-2} \mathrm{~d}^{-1}\right.$, located $60 \mathrm{~m}$ south from the northernmost VTP measurement location at the eastern shore; Fig. A1b). In order to estimate the radon activity of the groundwater, a groundwater sample was taken in a nearby piezometer (Fig. 1c of the paper). The water samples were analysed using the alpha spectrometer RAD7 (Durridge Company Inc., Bedford, MA, USA) with the Big Bottle RAD $\mathrm{H}_{2} \mathrm{O}$ extension. Analysing time of the RAD7 was extended to $3.5 \mathrm{~h}$ or longer to reduce measurement uncertainties. To remove background concentration of radon in the measurement device, the device was purged for at least $3.5 \mathrm{~h}$ with fresh air between water samples. Relative humidity was kept below $8 \%$ during measurements. Most of the samples were analysed in the first days directly after sampling. Maximum delay between sampling and analysis was 1 week. The data were decay corrected based on the time between sampling and analysis.

\section{A3 Results}

To test the capability of radon as a tracer of groundwater inflow at Lake Hinnensee, we took two samples at VTP measurement locations where LGD rates were known to be significantly different. The radon activity at the sampling location with stronger LGD was significantly higher $\left(787 \mathrm{~Bq} \mathrm{~m}^{-3}\right)$ than the radon activity in the other sample $\left(90 \mathrm{~Bq} \mathrm{~m}^{-3}\right)$. Groundwater had a radon activity of $12151 \mathrm{~Bq} \mathrm{~m}^{-3}$. Radon activities in lake water samples taken offshore ranged between 0 and $103 \mathrm{~Bq} \mathrm{~m}^{-3}$, with a median of $41 \mathrm{~Bq} \mathrm{~m}^{-3}$ and an IQR of $30 \mathrm{~Bq} \mathrm{~m}^{-3}$. Radon activities in the uppermost quartile $\left(>54 \mathrm{~Bq} \mathrm{~m}^{-3}\right.$ ) were measured in the northern part of the lake and at one sampling point in the central part of the lake $100 \mathrm{~m}$ east of the southern temperature logger chain. The three southernmost points had lowest radon activities $\left(0-22 \mathrm{~Bq} \mathrm{~m}^{-3}\right)$ (Fig. A1).

\section{A4 Discussion}

Measured radon activities of lake samples indicate groundwater inflow, but activities were low. Sampling locations were mainly located in the epilimnion, where lake levels were too shallow to allow for a thermocline. In the epilimnion, the lake water is assumed to be well mixed (Kluge et al., 2012). Therefore, it is possible that the homogeneous and very low radon activity in the deeper parts of the lake results from groundwater inflow from the near-shore area. Comparison of radon activity at the location with strong groundwater inflow close to the shore showed a significant effect of local groundwater inflow on radon activities, despite the likely wind-driven radon losses to the atmosphere. As these wind-driven losses are likely to be higher in the shallow near-shore areas where wave-action also leads to increased mixing, we assume that samples taken at the lake bottom at the centre of the lake are likely to be less influenced by losses to the atmosphere, so that low activities are unlikely to occur due to degassing losses alone. Furthermore, the sample taken close to corner 3 (Fig. A1b), where FO-DTS measurements showed a groundwater inflow signal, had the strongest radon activity of the offshore water samples $\left(103 \mathrm{~Bq} \mathrm{~m}^{-3}\right)$. Thus, we assume that enhanced radon activities resulted from local groundwater inflow and low radon activities offshore indicate insignificant groundwater inflow in the deeper parts of the lake. These results complement the results of the fibreoptic temperature measurements and furthermore provide the information that offshore-LGD rates south of the DTS cable (in the main body of the lake) are also likely to be low. 

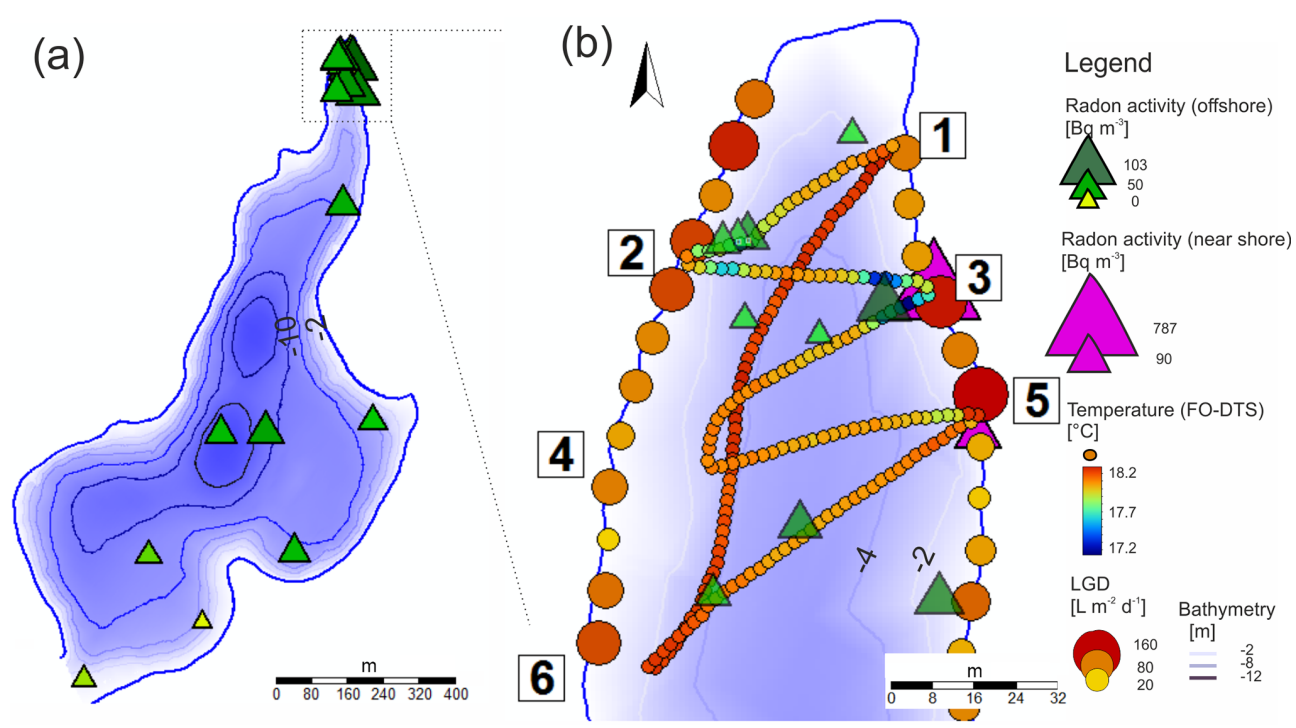

Figure A1. Radon activities measured in September 2013 and August 2014. LGD rates along the shoreline were derived from VTPs measured in June 2012. The DTS-derived temperature anomalies and the LGD rates along the shoreline are given for reference. 
Author contributions. CT and TB designed the experiments, discussed results and wrote the paper together. CT carried out the field measurements and the data analysis.

Competing interests. The authors declare that they have no conflict of interest.

Acknowledgements. This study is a contribution to the Virtual Institute of Integrated Climate and Landscape Evolution Analysis - ICLEA - of the Helmholtz Association. We would like to thank Lisei Köhn, Christian Budach, Sigfried Tusche, Philip Müller, Markus Morgner, Henriette Wilke and Knut Günther for their help in the field, the divers Silke Oldorff and Frank Kroll for their help laying out the FO-DTS cable and the Mueritz National Park authorities for their cooperation. Furthermore we thank Matthias Munz and Jana Carus for helpful discussions in the early stage of the manuscript. Bathymetry data were provided by the Ministerium für Landwirtschaft, Umwelt und Verbraucherschutz MecklenburgVorpommern. The study took place in the TERENO observatory of north-east Germany funded by the Helmholtz Association. We thank the anonymous reviewers for their very helpful comments that greatly improved the manuscript.

The article processing charges for this open-access

publication were covered by a Research

Centre of the Helmholtz Association.

Edited by: Thom Bogaard

Reviewed by: three anonymous referees

\section{References}

Bear, J.: Dynamics of fluids in porous media, Elsevier, New York, 1972.

Blume, T., Krause, S., Meinikmann, K., and Lewandowski, J.: Upscaling lacustrine groundwater discharge rates by fiber-optic distributed temperature sensing, Water Resour. Res., 49, 79297944, https://doi.org/10.1002/2012wr013215, 2013.

Born, S. M., Smith, S. A., and Stephenson, D. A.: Hydrogeology of glacial-terrain lakes, with management and planning applications, J. Hydrol., 43, 7-43, https://doi.org/10.1016/00221694(79)90163-x, 1979.

Bredehoeft, J. D. and Papaopulos, I. S.: Rates of vertical groundwater movement estimated from the Earth's thermal profile, Water Resour. Res., 1, 325-328, https://doi.org/10.1029/WR001i002p00325, 1965.

Brenning, A.: Statistical Geocomputing combining R and SAGA: The Example of Landslide susceptibility Analysis with generalized additive Models, in: SAGA - Seconds Out, edited by: Böhner, J., Blaschke, T., and Montanarella, L., Hamburger Beiträge zur Physischen Geographie und Landschaftsökologie, 19, 23-32, 2008.

Brock, T. D., Lee, D., Janes, D., and Winek, D.: Groundwater seepage as a nutrient source to a drainage lake, Lake Mendota, Wisconsin, Water Res., 16, 1255-1263, https://doi.org/10.1016/0043-1354(82)90144-0, 1982.
Caruso, A., Ridolfi, L., and Boano, F.: Impact of watershed topography on hyporheic exchange, Adv. Water Resour., 94, 400-411, https://doi.org/10.1016/j.advwatres.2016.06.005, 2016.

Chapuis, R. P.: Shape factors for permeability tests in boreholes and piezometers, Ground Water, 27, 647-654, https://doi.org/10.1111/j.1745-6584.1989.tb00478.x, 1989.

Cherkauer, D. S. and Nader, D. C.: Distribution of groundwater seepage to large surface-water bodies: the effect of hydraulic heterogeneities, J. Hydrol., 109, 151-165, https://doi.org/10.1016/0022-1694(89)90012-7, 1989.

Fleckenstein, J. H., Neumann, C., Volze, N., and Beer, J.: Raumzeitmuster des See-Grundwasser-Austausches in einem sauren Tagebaurestsee, Grundwasser, 14, 207-217, https://doi.org/10.1007/s00767-009-0113-1, 2009.

Gleeson, T., Marklund, L., Smith, L., and Manning, A. H.: Classifying the water table at regional to continental scales, Geophys. Res. Lett., 38, L05401, https://doi.org/10.1029/2010GL046427, 2011.

Grimm, V., Revilla, E., Berger, U., Jeltsch, F., Mooij, W. M., Railsback, S. F., Thulke, H.-H., Weiner, J., Wiegand, T., and DeAngelis, D. L.: Pattern-oriented modeling of agent-based complex systems: lessons from ecology, Science, 310, 987-991, https://doi.org/10.1126/science.1116681, 2005.

Haitjema, H. M. and Mitchell-Bruker, S.: Are water tables a subdued replica of the topography?, Groundwater, 43, 781-786, 2005.

Håkanson, L.: The influence of wind, fetch, and water depth on the distribution of sediments in Lake Vänern, Sweden, Can. J. Earth Sci., 14, 397-412, https://doi.org/10.1139/e77-040, 1977.

Hvorslev, M. J.: Time lag and soil permeability in ground-water observations, US Army Corps of Engineers, Vicksburg, Mississippi, Waterways Experiment Station Bulletin, 36, 1-50, 1951.

Jencso, K. G., McGlynn, B. L., Gooseff, M. N., Wondzell, S. M., Bencala, K. E., and Marshall, L. A.: Hydrologic connectivity between landscapes and streams: transferring reach- and plot-scale understanding to the catchment scale, Water Resour. Res., 45, W04428, https://doi.org/10.1029/2008wr007225, 2009.

Jencso, K. G., McGlynn, B. L., Gooseff, M. N., Bencala, K. E., and Wondzell, S. M.: Hillslope hydrologic connectivity controls riparian groundwater turnover: implications of catchment structure for riparian buffering and stream water sources, Water Resour. Res., 46, W10524, https://doi.org/10.1029/2009wr008818, 2010.

Kalbus, E., Reinstorf, F., and Schirmer, M.: Measuring methods for groundwater - surface water interactions: a review, Hydrol. Earth Syst. Sci., 10, 873-887, https://doi.org/10.5194/hess-10873-2006, 2006.

Kidmose, J., Nilsson, B., Engesgaard, P., Frandsen, M., Karan, S., Landkildehus, F., Søndergaard, M., and Jeppesen, E.: Focused groundwater discharge of phosphorus to a eutrophic seepage lake (Lake Væng, Denmark): implications for lake ecological state and restoration, Hydrogeol. J., 21, 1787-1802, https://doi.org/10.1007/s10040-013-1043-7, 2013.

Kishel, H. F. and Gerla, P. J.: Characteristics of preferential flow and groundwater discharge to Shingobee Lake, Minnesota, USA, Hydrol. Process., 16, 1921-1934, https://doi.org/10.1002/hyp.363, 2002.

Kluge, T., von Rohden, C., Sonntag, P., Lorenz, S., Wieser, M., Aeschbach-Hertig, W., and Ilmberger, J.: Localising 
and quantifying groundwater inflow into lakes using high-precision 222Rn profiles, J. Hydrol., 450, 70-81, https://doi.org/10.1016/j.jhydrol.2012.05.026, 2012.

Landon, M. K., Rus, D. L., and Harvey, F. E.: Comparison of instream methods for measuring hydraulic conductivity in sandy streambeds, Groundwater, 39, 870-885, https://doi.org/10.1111/j.1745-6584.2001.tb02475.x, 2001.

Lewandowski, J., Meinikmann, K., Nützmann, G., and Rosenberry, D. O.: Groundwater - the disregarded component in lake water and nutrient budgets, Part 2: effects of groundwater on nutrients, Hydrol. Process., 29, 2922-2955, https://doi.org/10.1002/hyp.10384, 2015.

McBride, M. S. and Pfannkuch, H. O.: The distribution of seepage within lakebeds, J. Res. US Geol. Surv., 3, 505-512, 1975.

Meinikmann, K., Lewandowski, J., and Nützmann, G.: Lacustrine groundwater discharge: combined determination of volumes and spatial patterns, J. Hydrol., 502, 202-211, https://doi.org/10.1016/j.jhydrol.2013.08.021, 2013.

Müller, J. and Bolte, A.: The use of lysimeters in forest hydrology research in north-east Germany, Landbauforsch. vTI AG, 59, 110, 2009.

Neumann, C., Beer, J., Blodau, C., Peiffer, S., and Fleckenstein, J. H.: Spatial patterns of groundwater-lake exchange - implications for acid neutralization processes in an acid mine lake, Hydrol. Process., 27, 3240-3253, https://doi.org/10.1002/hyp.9656, 2013.

Ono, M., Tokunaga, T., Shimada, J., and Ichiyanagi, K.: Application of continuous $222 \mathrm{Rn}$ monitor with dual loop system in a small lake, Ground water, 51, 706-713, https://doi.org/10.1111/gwat.12002, 2012.

$\mathrm{R}$ : A language and environment for statistical computing, $\mathrm{R}$ Foundation for Statistical Computing, Vienna, Austria, available at: https://www.R-project.org (last access: August 2015), 2016.

Rosenberry, D. O., Lewandowski, J., Meinikmann, K., and Nützmann, G.: Groundwater - the disregarded component in lake water and nutrient budgets, Part 1: effects of groundwater on hydrology, Hydrol. Process., 29, 2895-2921, https://doi.org/10.1002/hyp.10403, 2015.
Schmidt, C., Bayer-Raich, M., and Schirmer, M.: Characterization of spatial heterogeneity of groundwater-stream water interactions using multiple depth streambed temperature measurements at the reach scale, Hydrol. Earth Syst. Sci., 10, 849-859, https://doi.org/10.5194/hess-10-849-2006, 2006.

Schneider, R. L., Negley, T. L., and Wafer, C.: Factors influencing groundwater seepage in a large, mesotrophic lake in New York, J. Hydrol., 310, 1-16, https://doi.org/10.1016/j.jhydrol.2004.09.020, 2005.

Sebok, E., Duque, C., Kazmierczak, J., Engesgaard, P., Nilsson, B., Karan, S., and Frandsen, M.: High-resolution distributed temperature sensing to detect seasonal groundwater discharge into Lake Væng, Denmark, Water Resour. Res., 49, 5355-5368, https://doi.org/10.1002/wrcr.20436, 2013.

Shaw, G. D., White, E. S., and Gammons, C. H.: Characterizing groundwater-lake interactions and its impact on lake water quality, J. Hydrol., 492, 69-78, https://doi.org/10.1016/j.jhydrol.2013.04.018, 2013.

Stonestrom, D. A. and Constantz, J.: Heat as a tool for studying the movement of ground water near streams, S. Dept. of the Interior, US Geological Survey, Reston, Virginia, 2003.

Tóth, J.: A theoretical analysis of groundwater flow in small drainage basins, J. Geophys. Res., 68, 4795-4812, https://doi.org/10.1029/JZ068i016p04795, 1963.

Ukil, A., Braendle, H., and Krippner, P.: Distributed temperature sensing: review of technology and applications, IEEE Sens. J., 12, 885-892, https://doi.org/10.1109/jsen.2011.2162060, 2012.

Vainu, M., Terasmaa, J., and Häelm, M.: Relations between groundwater flow in an unconfined aquifer and seepage patterns in a closed-basin lake in glacial terrain, Hydrol. Res., 46, 325, https://doi.org/10.2166/nh.2014.197, 2015.

Winter, T. C., Harvey, J. W., Franke, O. L., and Alley, W. M.: Ground water and surface water - a single resource, U.S. Geol. Surv., Denver, Colorado, Rep. Circular, 1139, 1998.

Winter, T. C.: Relation of streams, lakes, and wetlands to groundwater flow systems, Hydrogeol. J., 7, 28-45, https://doi.org/10.1007/s100400050178, 1999. 